\title{
Uptake mechanisms of selenium oxyanions during the ferrihydrite-hematite recrystallization
}

DOI:

10.1016/j.gca.2017.03.004

\section{Document Version}

Accepted author manuscript

Link to publication record in Manchester Research Explorer

\section{Citation for published version (APA):}

Börsig, N., Scheinost, A. C., Shaw, S., Schild, D., \& Neumann, T. (2017). Uptake mechanisms of selenium oxyanions during the ferrihydrite-hematite recrystallization. Geochimica et Cosmochimica Acta, 206, 236-253. https://doi.org/10.1016/j.gca.2017.03.004

\section{Published in:}

Geochimica et Cosmochimica Acta

\section{Citing this paper}

Please note that where the full-text provided on Manchester Research Explorer is the Author Accepted Manuscript or Proof version this may differ from the final Published version. If citing, it is advised that you check and use the publisher's definitive version.

\section{General rights}

Copyright and moral rights for the publications made accessible in the Research Explorer are retained by the authors and/or other copyright owners and it is a condition of accessing publications that users recognise and abide by the legal requirements associated with these rights.

\section{Takedown policy}

If you believe that this document breaches copyright please refer to the University of Manchester's Takedown Procedures [http://man.ac.uk/04Y6Bo] or contact uml.scholarlycommunications@manchester.ac.uk providing relevant details, so we can investigate your claim.

\section{OPEN ACCESS}




\section{Uptake mechanisms of selenium oxyanions during the ferrihydrite-hematite recrystallization}

Nicolas Börsig ${ }^{\mathrm{a}, *}$, Andreas C. Scheinost ${ }^{\mathrm{b}, \mathrm{c}}$, Samuel Shaw ${ }^{\mathrm{d}}$, Dieter Schild ${ }^{\mathrm{e}}$, Thomas Neumann ${ }^{\text {a }}$

${ }^{a}$ Karlsruhe Institute of Technology (KIT), Institute of Applied Geosciences, Adenauerring 20b, 76131 Karlsruhe, Germany

${ }^{\mathrm{b}}$ Helmholtz-Zentrum Dresden-Rossendorf (HZDR), Institute of Resource Ecology, Bautzner Landstraße 400, 01328 Dresden, Germany

${ }^{c}$ The Rossendorf Beamline (ROBL) at ESRF, 38043 Grenoble, France

${ }^{\mathrm{d}}$ The University of Manchester, School of Earth, Atmospheric and Environmental Sciences, Manchester, M13 9PL, United Kingdom

${ }^{\text {e }}$ Karlsruhe Institute of Technology (KIT), Institute for Nuclear Waste Disposal, Hermann-von-Helmholtz-Platz 1, 76344 Eggenstein-Leopoldshafen, Germany

*Corresponding author: Tel.: +49 721 608-44878; nicolas.boersig@ @it.edu (N. Börsig)

Keywords: $\quad$ selenite, selenate, iron oxide, immobilization, retention, adsorption, incorporation, occlusion, XPS, XAS, EXAFS

\section{Abstract}

Se is an essential nutrient at trace levels, but also a toxic environmental contaminant at higher concentrations. The mobility of the trace element Se in natural environments is mainly controlled by the occurrence of the highly soluble Se oxyanions - selenite [Se(IV)] and selenate $[\mathrm{Se}(\mathrm{VI})]$ - and their interaction with geological materials. Since iron oxides are ubiquitous in nature, many previous studies investigated Se retention by adsorption onto iron oxides. However, little is known about the retention of Se oxyanions during the formation process of iron oxides. In this paper, we therefore studied the immobilization of Se oxyanions during the crystallization of hematite from ferrihydrite. In coprecipitation studies, hematite was synthesized by the precipitation and aging of ferrihydrite in an oxidized $\mathrm{Se}(\mathrm{IV})$ - or $\mathrm{Se}(\mathrm{VI})$-containing system ( $\mathrm{pH}$ 7.5). Hydrochemical data of these batch experiments revealed the complete uptake of all available Se(IV) up to initial concentrations of $\mathrm{c}(\mathrm{Se})_{0}=10^{-3} \mathrm{~mol} / \mathrm{L}$ $(\mathrm{m} / \mathrm{V}$ ratio $=9.0 \mathrm{~g} / \mathrm{L})$, while the retention of $\mathrm{Se}(\mathrm{VI})$ was low $\left(\max .15 \%\right.$ of $\left.\mathrm{c}(\mathrm{Se})_{0}\right)$. In case of high initial Se(IV) concentrations, the results also demonstrated that the interaction of Se with ferrihydrite can affect the type of the final transformation product. Comparative adsorption studies, performed at identical conditions, allowed a distinction between pure adsorption and coprecipitation and showed a significantly higher Se retention by coprecipitation than by 
adsorption. Desorption studies indicated that Se coprecipitation leads to the occurrence of a resistant, non-desorbable Se fraction. According to time-resolved studies of $\mathrm{Se}(\mathrm{IV})$ or $\mathrm{Se}(\mathrm{VI})$ retention during the hematite formation and detailed spectroscopic analyses (XPS, XAS), this fraction is the result of an incorporation process, which is not attributable to Fe-for-Se substitution or the Se occupation of vacancies. Se initially adsorbs to the ferrihydrite surface, but after the transformation of ferrihydrite into hematite, it is mostly incorporated by hematite. In systems without mineral transformation, however, Se remains as a sorption complex. In case of $\mathrm{Se}(\mathrm{VI})$, an outer-sphere complex forms, while $\mathrm{Se}(\mathrm{IV})$ forms a mixture of bidentate mononuclear edge-sharing and bidentate binuclear corner-sharing inner-sphere complexes. The results of this study demonstrate that incorporation of Se oxyanions by hematite is an important retention mechanism in addition to pure adsorption, which may affect the migration and immobilization of Se oxyanions in natural systems or polluted environments.

\section{Introduction}

Selenium (Se) is a trace element of special concern, since it is an essential nutrient for organisms at low concentrations, but a toxic contaminant at slightly higher concentrations (Lenz and Lens, 2009). Of concern are therefore not only Se-deficient agricultural soils in certain regions of the World, but also Se contaminations of soils or wastewaters caused by natural and/or anthropogenic factors (Dhillon and Dhillon, 2003; Lenz and Lens, 2009; Christophersen et al., 2012; Winkel et al., 2012). In soils in contact with the atmosphere, the thermodynamically favored Se species are the oxyanions selenate [Se(VI)] and selenite [Se(IV)]. These higher Se oxidation states are of particular relevance for the biogeochemical behavior of Se in soils and waters, since Se(IV) and Se(VI) form species with high solubility (Séby et al., 2001) which, in turn, is responsible for a high environmental mobility, bioavailability and toxicity (Dhillon and Dhillon, 2003; Lenz and Lens, 2009; Winkel et al., 2015). The fate of dissolved $\mathrm{Se}(\mathrm{IV})$ and $\mathrm{Se}(\mathrm{VI})$ species in subsurface systems is primarily determined by interaction with mineral phases, including processes such as adsorption, incorporation, and reductive precipitation, which are the key immobilization mechanisms (Chen et al., 1999; Grambow, 2008). However, most natural materials like clays or silicate minerals show only a restricted retention capacity for Se oxyanions.

In this context, crystalline iron (oxyhydr)oxides minerals (e.g. hematite and goethite) and their metastable precursors (e.g. ferrihydrite) are of great importance as they are widespread 
in nature and capable of anion sorption (Roh et al., 2000; Sparks, 2003; Adegoke et al., 2013; Blume et al., 2016). This is the reason why, in particular, the mechanisms of Se oxyanion adsorption to iron oxide surfaces have been investigated in detail by a large number of previous studies. They show that adsorption of $\mathrm{Se}(\mathrm{IV})$ and $\mathrm{Se}(\mathrm{VI})$ onto iron oxides can be very efficient at lower $\mathrm{pH}$, but is limited under near-neutral and alkaline $\mathrm{pH}$ conditions (e.g. Balistrieri and Chao, 1990; Zhang and Sparks, 1990; Parida et al., 1997; Duc et al., 2003; Martínez et al., 2006; Rovira et al., 2008). This tendency is independent of the type of iron oxide, since alkaline conditions generally lead to the formation of a negative charge at the iron oxide surface and therefore to a poor adsorption of anionic species (Fernández-Martínez and Charlet, 2009). Moreover, all iron oxides show a relatively high adsorption capacity for $\mathrm{Se}(\mathrm{IV})$ and there is only little release of Se(IV) with increasing ionic strength. Unlike Se(IV), adsorption of $\mathrm{Se}(\mathrm{VI})$ is much lower and is strongly influenced by the presence of competing anions (Hayes et al., 1987; Su and Suarez, 2000; Rietra et al., 2001; Jordan et al., 2013; Jordan et al., 2014). Most authors suggest the difference between Se(IV) and Se(VI) adsorption is due to the nature of the chemical attachment and the formation of different types of adsorption complexes. Spectroscopic investigations as well as surface complexation modeling reveal that the adsorption of Se(IV) onto iron oxides is usually the result of innersphere complexation (Fernández-Martínez and Charlet, 2009) with a mostly bidentate character, e.g. for hematite (Catalano et al., 2006; Duc et al., 2006). By contrast, the poor adsorption of $\mathrm{Se}(\mathrm{VI})$ and the strong impact of competing anions has been attributed to the formation of outer-sphere complexes (Hayes et al. 1987). However, more recent studies suggest that adsorption of $\mathrm{Se}(\mathrm{VI})$ can occur via both inner-sphere and outer-sphere complexation (Wijnja and Schulthess, 2000; Peak and Sparks, 2002; Jordan et al., 2013). The type of surface complexation depends on $\mathrm{pH}$, ionic strength, the nature of the iron oxide mineral and its surface loading (Peak and Sparks, 2002; Fukushi and Sverjensky, 2007; Fernández-Martínez and Charlet, 2009). Nevertheless, the results of a range of studies of the $\mathrm{Se}(\mathrm{VI})$ adsorption mechanisms onto goethite, ferrihydrite or hematite (Manceau and Charlet, 1994; Wijnja and Schulthess, 2000; Rietra et al., 2001; Peak and Sparks, 2002; Fukushi and Sverjensky, 2007; Das et al., 2013) remain to some extent contradictory.

In addition, there is to the best of our knowledge no research available investigating the possible role of the incorporation of Se oxyanions into iron oxide minerals. The incorporation of anionic trace elements by iron oxides was demonstrated in several publications. These studies revealed oxyanion incorporation or occlusion by hematite for $\mathrm{Si}(\mathrm{IV})$ (Liu et al., 2012), P(V) (Gálvez et al., 1999a; Gálvez et al., 1999b), As(V) (Bolanz et al., 2013; Das et al., 
2015), V(V) (Sracek, 2015) and Tc(VII) (Skomurski et al., 2010). For this reason, it is conceivable that a retention mechanism on the basis of incorporation also exists for the both Se oxyanions, $\mathrm{Se}(\mathrm{IV})$ and $\mathrm{Se}(\mathrm{VI})$, and that such mechanisms could affect the migration of dissolved Se species.

However, incorporation can only be relevant in cases where iron oxide phases interact with dissolved species during their formation or transformation, including recrystallization or sorption induced crystal growth. Since the formation pathway of crystalline iron oxides commonly includes amorphous metastable intermediates (Cornell and Schwertmann, 2003), such processes are very common in natural systems like soils. Hematite $\left[\alpha-\mathrm{Fe}_{2} \mathrm{O}_{3}\right]$ and goethite $[\alpha-\mathrm{FeOOH}]$, the most stable and widespread iron oxides under aerobic conditions, usually result from amorphous ferrihydrite that recrystallizes in one of the two phases after a certain period of time. The type of reaction product depends on the environmental setting, whereby a near-neutral $\mathrm{pH}$, higher temperatures or lower water activities favor a transformation of ferrihydrite into hematite (Kämpf et al,, 2011). As these parameters are strongly influenced by the prevailing climatic conditions, goethite represents the dominant transformation product in soils of all climate regions, whereas the occurrence of hematite is usually limited to tropical and subtropical soils (Blume et al., 2016). Besides that, both minerals also differ in the nature of their formation mechanism. While the transformation of ferrihydrite to goethite is caused by a dissolution-precipitation process, the recrystallization into hematite is based on an aggregation and phase transformation process followed by particle growth (Cornell and Schwertmann, 2003; Adegoke et al., 2013; Soltis et al., 2016). These differences in the recrystallization mechanism are the reason why we focused on hematite instead of goethite to identify a potential incorporation of Se oxyanions, as an incorporation should be more likely in case of an internal dehydration and rearrangement than in case of an interim ferrihydrite dissolution.

The aim of our work was, therefore, to determine whether the incorporation of Se oxyanions into hematite can occur under a range of geochemical conditions. For this, we characterized the interaction of Se oxyanions with hematite during its crystallization from ferrihydrite via coprecipitation experiments, and compared these results with those from Se adsorption to hematite. In contrast to many previous Se adsorption studies, all experiments were conducted at a near-neutral $\mathrm{pH}$ and thus under conditions that are comparable to various systems where migration of Se oxyanions might be crucial. This includes the critical zone (e.g. Bajaj et al., 2011; Winkel et al., 2015) but also Se contaminated sites that are characterized by neutral pH 
conditions (e.g. Adams and Pickett, 1998; Das et al., 2013). Through the combination of hydrochemical data and detailed analyses of the solid phases via X-Ray Diffraction (XRD), Scanning Electron Microscopy (SEM), X-ray Photoelectron Spectroscopy (XPS) and X-ray Absorption Spectroscopy (XAS), it was possible for the first time to prove the presence of an incorporated Se fraction within hematite, to identify the nature of the Se retention mechanism and to differentiate between Se coprecipitation and adsorption in terms of retention capacity and stability. These results provide useful information about long-term Se immobilization mechanisms in addition to pure adsorption, and contribute to a better global understanding of the Se retention processes in various fields.

\section{Materials and Methods}

\subsection{Materials}

All solutions were made of analytically pure grade chemicals and de-ionized Milli-Q water $\left(18.2{\mathrm{M} \Omega \mathrm{cm}^{-1}}^{-1}\right.$. The Se stock solutions used in the coprecipitation and adsorption experiments were prepared by dissolving defined quantities of $\mathrm{Na}_{2} \mathrm{SeO}_{3}$ or $\mathrm{Na}_{2} \mathrm{SeO}_{4} \cdot 10 \mathrm{H}_{2} \mathrm{O}$ in Milli-Q water to receive total $\mathrm{Se}(\mathrm{IV})$ or $\mathrm{Se}(\mathrm{VI})$ concentrations of $0.1 \mathrm{~mol} / \mathrm{L}$ and $1.0 \mathrm{~mol} / \mathrm{L}$.

\subsection{Preparation of synthetic hematite and ferrihydrite}

Hematite $(\mathrm{Hm})$ was synthesized in the laboratory by using a slightly modified method of Schwertmann and Cornell (2000) in order to reflect formation of hematite from ferrihydrite (Fh) under conditions that are more comparable to natural than to laboratory conditions in terms of the main hydrochemical parameters. This implies the prerequisite that the mineral formation took place in an aquatic aerobic system under neutral to slightly alkaline $\mathrm{pH}$ conditions and at moderate temperatures. Hematite was synthesized by dissolving $40 \mathrm{~g}$ $\mathrm{Fe}\left(\mathrm{NO}_{3}\right)_{3} \cdot 9 \mathrm{H}_{2} \mathrm{O}$ in $500 \mathrm{ml}$ Milli-Q water. After the addition of $300 \mathrm{ml} 1 \mathrm{M} \mathrm{KOH}$ and the immediate precipitation of ferrihydrite (red-brownish compound), the suspension was titrated and buffered with $50 \mathrm{ml}$ of $1 \mathrm{M} \mathrm{NaHCO}_{3}$ solution before the final $\mathrm{pH}$ of 7.5 was adjusted with additional $25 \mathrm{ml}$ of $1 \mathrm{M} \mathrm{KOH}$. All solutions were preheated to temperatures of $50^{\circ} \mathrm{C}$ and stirred continuously during the mixing. Afterwards, the flask was sealed and the prepared suspension stored in an oven at $50^{\circ} \mathrm{C}$ for 10 days. Slightly increased temperatures of $50^{\circ} \mathrm{C}$ were chosen to favor transformation of ferrihydrite into hematite rather than goethite, and to speed up the mineral transformation processes (Schwertmann et al., 2004). The procedure for the synthesis of ferrihydrite was identical, except that the synthesis process was terminated after 1 hour. With approx. $8 \mathrm{~g}$ precipitated iron oxide forming, the mass to volume ratio $(\mathrm{m} / \mathrm{V})$ 
between hematite/ferrihydrite and the aqueous solution was approx. $9.0 \mathrm{~g} / \mathrm{L}$ during these batch experiments. At the end of the respective reaction time, the precipitates were decanted and centrifuged. While a sample of the solutions was taken for the analysis of the $\mathrm{Fe}$ concentration and $\mathrm{pH}$, the solids were washed 3 times with Milli-Q water to remove $\mathrm{NO}_{3}^{-}$and $\mathrm{HCO}_{3}^{-}$impurities. Synthesized hematite samples were then dried at moderate temperatures of $40^{\circ} \mathrm{C}$, while ferrihydrite samples were freeze-dried to avoid re-crystallization processes. After that, the aggregated particles were ground with an agate mortar and stored until the analysis or the use in subsequent experiments.

\subsection{Selenium coprecipitation studies}

Since $\mathrm{Se}(\mathrm{IV})$ or $\mathrm{Se}(\mathrm{VI})$ speciation during the coprecipitation experiment is controlled by the hydrochemical conditions during the hematite synthesis, the procedure of sample preparation was almost identical to the synthesis of pure hematite. To investigate the $\mathrm{Se}(\mathrm{VI})$ and $\mathrm{Se}(\mathrm{VI})$ uptake by coprecipitation, different volumes of Se stock solutions were added to the dissolved $\mathrm{Fe}^{3+}$ prior to the beginning of the first mineral precipitation. Furthermore, the residual Se concentrations after the experiments were analyzed and a part of the solid sample was dried without prior washing with Milli-Q water in order to preserve the surface characteristics of the sample. Added Se stock solution volumes were calculated to obtain initial Se concentrations of $10^{-4}-10^{-2} \mathrm{~mol} / \mathrm{L}$ after the mixing of all solutions $(\mathrm{m} / \mathrm{V}$ ratio $=9.0 \mathrm{~g} / \mathrm{L})$. These relatively high Se concentrations reflect extreme natural amounts but were necessary to increase the Se percentage within the solid iron oxide samples in order to improve the $\mathrm{Se}$ detection for the subsequent analyses. Different initial Se concentrations were used to vary the $\mathrm{Fe} / \mathrm{Se}$ ratios in the solid samples.

Time-resolved investigations of the re-crystallization of hematite were carried out to examine the role of the precursor phase ferrihydrite onto Se retention. For this, samples of both the solid precipitate and the solution were collected and analyzed after several time intervals (10 min, 1 h, $6 \mathrm{~h}, 1 \mathrm{~d}, 2 \mathrm{~d}, 4 \mathrm{~d}, 6 \mathrm{~d}, 8 \mathrm{~d}, 10 \mathrm{~d}$ ) during the hematite formation process.

\subsection{Selenium adsorption studies}

For comparison with the coprecipitation experiments, we studied also Se adsorption on pure hematite in batch experiments. The experimental settings were kept similar to the conditions at the end of the coprecipitation experiments. This mainly includes the parameters $\mathrm{pH}$, ionic strength, and the $\mathrm{m} / \mathrm{V}$ ratio. The ionic strength was calculated under the assumption that the extremely low solubility of hematite at $\mathrm{pH} 7.5$ leads to the precipitation of the entire initial 
$\mathrm{Fe}(\mathrm{III})$ quantity, resulting in a residual ionic strength of $0.43 \mathrm{~mol} / \mathrm{L}$. Since the synthesis is mainly based on the use of $\mathrm{Fe}\left(\mathrm{NO}_{3}\right)_{3}$ and $\mathrm{KOH}$ solutions, the ionic strength is determined primarily by $\mathrm{KNO}_{3}$.

For the investigation of the $\mathrm{Se}(\mathrm{IV})$ and $\mathrm{Se}(\mathrm{VI})$ uptake by adsorption as a function of the initial Se concentrations in the range $10^{-4}-10^{-2} \mathrm{~mol} / \mathrm{L}, 40 \mathrm{ml}$ of $0.43 \mathrm{M} \mathrm{KNO}_{3}$, which contained a defined volume of a Se stock solution, was added to $361.8 \mathrm{mg}$ of pure hematite powder in sealable flasks. Subsequently, the $\mathrm{pH}$ was adjusted to 7.5 by dropwise addition of either $0.1 \mathrm{M}$ $\mathrm{HNO}_{3}$ or $\mathrm{KOH}$ solutions. Afterwards, the flasks were sealed and shaken for 48 hours to ensure that adsorption equilibrium was achieved. Due to the strong buffer ability of the hematite, the $\mathrm{pH}$ was checked after 24 and 45 hours and if necessary adjusted again to $\mathrm{pH}$ 7.5. The subsequent treatment of the samples was identical to the procedure after the coprecipitation studies. This approach allowed the preparation of hematite samples with varying content of adsorbed Se.

In addition to the adsorption studies with varying initial Se concentrations, some further similar experiments were carried out to study the Se(IV) and Se(IV) adsorption onto hematite depending on $\mathrm{pH}$ and the ionic strength. This provides information on the specific effect of the $\mathrm{pH}$ value and the background electrolyte concentration for the interaction processes during the mineral formation.

\subsection{Desorption studies}

$\mathrm{Se}(\mathrm{IV})$ and $\mathrm{Se}(\mathrm{VI})$ desorption was investigated by two procedures to characterize and compare the stability of the retention mechanisms. In the first procedure, batch experiments were carried by mixing a specific amount of dried hematite powder from previous Se adsorption or coprecipitation studies with the desorption solution in the ratio $\mathrm{m} / \mathrm{V}=9.0 \mathrm{~g} / \mathrm{L}$. The desorption solution was made of $0.01 \mathrm{M} \mathrm{KNO}_{3}$ with a $\mathrm{pH}$ of 12 (adjusted with $\mathrm{KOH}$ ) to exploit the limited adsorption capacity of hematite under alkaline conditions and to achieve a maximum removal of adsorbed Se from the hematite surface. The $\mathrm{pH}$ was still low enough to avoid the dissolution of the hematite phase. After mixing, the suspensions were shaken for 24 hours, then centrifuged and decanted. The residual supernatants were filtered, before $\mathrm{pH}$ was measured and the $\mathrm{Se}$ and $\mathrm{Fe}$ concentration in the aqueous phase was analyzed. This procedure was repeated three times and the total amount of removed Se was calculated as the sum of each desorption step. This desorption studies enabled also the preparation of hematite samples with a low fraction of adsorbed $\mathrm{Se}(\mathrm{IV})$ or $\mathrm{Se}(\mathrm{VI})$. 
In the second procedure, Se desorption from Se(IV)-bearing hematite and ferrihydrite samples was studied as a function of $\mathrm{OH}^{-}$concentration. The used technique is based on a method of Doornbusch et al. (2015) for iron oxide dissolution, but was adjusted for use under alkaline conditions. For this purpose, a specific amount of Se-bearing iron oxide powder was treated several times with $\mathrm{NaOH}$ of various concentrations $(\mathrm{m} / \mathrm{V}=3.4 \mathrm{~g} / \mathrm{L})$. In these experiments, $\mathrm{NaOH}$ was used instead of $\mathrm{KOH}$ as $\mathrm{NaOH}$ generates solutions with lower ionic strengths, which reduced difficulties during the subsequent sample analysis and enabled the use of higher $\mathrm{OH}^{-}$concentrations. In each step, the mixture was allowed to react for $30 \mathrm{~min}$, before the suspension was centrifuged and a sample of the supernatant was collected for $\mathrm{Fe}$ and $\mathrm{Se}$ analysis. The remaining supernatant was then discarded and replaced by the next solution with higher $\mathrm{OH}^{-}$concentration. Overall, eight desorption steps with increasing $\mathrm{OH}^{-}$ concentrations of $10^{-5}, 10^{-4}, 0.001,0.005,0.01,0.05,0.1$ and $0.5 \mathrm{~mol} / \mathrm{L}$ were used to study the effect of $\left[\mathrm{OH}^{-}\right]$on the desorption behavior. After the last $\mathrm{NaOH}$ solution, the remaining solid was reacted with $6 \mathrm{M} \mathrm{HCl}$ for $48 \mathrm{~h}$ to dissolve completely the iron oxide. This allowed the determination of the total $\mathrm{Se}$ and $\mathrm{Fe}$ contents of the solid phase.

\subsection{Analytical techniques}

\subsubsection{Dissolved selenium and iron concentrations}

After centrifugation and filtration $(0.2 \mu \mathrm{m}$ filter), all supernatants were acidified with concentrated high-purity $\mathrm{HNO}_{3}(50 \mu \mathrm{L})$. The Se and $\mathrm{Fe}$ concentrations in the aqueous phase were determined by ICP-OES or ICP-MS depending on the concentrations. For amounts higher than $1 \mathrm{mg} / \mathrm{L}$, measurements were performed on ICP-OES using a Varian 715ES. Analysis of samples with lower $\mathrm{Fe}$ and Se concentrations were carried out on an X-Series 2 ICP-MS (Thermo Fisher Scientific Inc.). Further measurement parameters are described in the Supporting Information. The lower detection limits were approx. $0.3 \mu \mathrm{g} / \mathrm{L}$ for both Se and Fe. Throughout the analyses of both ICP methods, a certified reference solution was used as standard.

\subsubsection{Characterization of the solid phases}

At the end of each batch experiment, the dried solid samples were characterized by several techniques. X-Ray Diffraction (XRD) was used for analysis of the purity and composition of the synthesized solid materials and performed on a Bruker D8 Advance X-ray diffractometer with $\mathrm{Cu} \mathrm{K} \alpha$ radiation $(\lambda=1.5406 \AA)$ and a LynxEye detector. All samples were prepared from powders except for the samples of the time-resolved investigation of the ferrihydrite 
transformation. These samples were prepared by drying small volumes of suspension directly on the XRD sample holder. XRD patterns of synthesized hematite were compared with hematite references (ICDD PDF-2 database) and showed that pure hematite was formed at $50^{\circ} \mathrm{C}$ without any evidences of contamination by goethite or other crystalline Fe oxides. For synthesized ferrihydrite, the XRD analysis revealed the formation of the most poorly crystalline ferrihydrite form, the 2-line ferrihydrite, which is identifiable by 2 broad peaks in the XRD plot with maxima at $2 \theta$ of $\sim 35^{\circ}$ and $\sim 62^{\circ}(\mathrm{Cu} \mathrm{K \alpha})$ (Supporting Information Fig. A.1).

BET measurements (Brunauer et al., 1938) were conducted on selected hematite and ferrihydrite samples using a Quantachrome Autosorb 1-MP and 11-point BET-argon isotherms recorded to calculate the specific surface areas (SSA). Prior to the measurement, the sample were outgassed in vacuum at $95^{\circ} \mathrm{C}$ overnight to remove water and other volatile surface contaminations. The measurements gave a specific surface area of $65 \mathrm{~m}^{2} / \mathrm{g}$ for pure hematite and of $243 \mathrm{~m}^{2} / \mathrm{g}$ for pure ferrihydrite. The value of ferrihydrite is in good agreement with the given BET results of $200-320 \mathrm{~m}^{2} / \mathrm{g}$ for 2-line ferrihydrite of Schwertmann and Cornell (2000), whereas the values for hematite are significantly higher than their published data $\left(20-25 \mathrm{~m}^{2} / \mathrm{g}\right)$. However, hematites produced from solution can generally show SSA up to $90 \mathrm{~m}^{2} / \mathrm{g}$ depending on their particle size and shape (Cornell and Schwertmann, 2003). The observed difference can therefore be explained by the lower synthesis temperature of $50^{\circ} \mathrm{C}$ compared to the original suggested $90^{\circ} \mathrm{C}$, which results in smaller particle sizes and a higher porosity of the hematite crystals.

The total Se content of the solid phases was determined by polarized Energy Dispersive X-ray Fluorescence Spectroscopy (pEDXRF) using an Epsilon 5 (PANalytical) equipped with a W $\mathrm{X}$-ray tube and a Ge detector. A Mo target was selected as polarizing secondary target and the measurement period was $500 \mathrm{~s}$, resulting in a lower detection limit for Se of $10 \mathrm{ppm}$ and an analytical precision of $\pm 5 \%$. Standards consisting of mixtures of synthesized hematite and known amounts of a Se reference material (pure $\mathrm{Se}(0)$ powder or certified Se reference solution) were utilized for calibration.

Scanning Electron Microscopy with Energy Dispersive X-ray Spectroscopy (SEM/EDX) was used to characterize the morphology of the solid phases and to assess the size of the particles. Images were recorded using a LEO 1530 (Zeiss Inc.) SEM with a NORAN System SIX (Thermo Electron Corp.) EDX-System. The dried powder samples were coated with Pt after they were mounted on sample holders via double-sided carbon tape. The characterization by 
secondary electron imaging of the pure synthesis product revealed that hematite consists of aggregated bulky particles with a size of 50 to $100 \mathrm{~nm}$ (cf. chapter 3.3)

In order to examine the Se oxidation state and to identify ionic species on the hematite surface, X-ray Photoelectron Spectroscopy (XPS) measurements were performed using a PHI 5000 VersaProbe II (ULVAC-PHI Inc.) Further measurement parameters are described in the Supporting Information. By means of XPS analysis, it was possible to characterize the sorbed surface species and the chemical composition of unwashed hematite samples (Supporting Information - Table A.1). As expected, higher amounts of $\mathrm{C}$ and lower amounts of $\mathrm{N}, \mathrm{K}$ and $\mathrm{Na}$ can be found beside $\mathrm{Fe}$ and $\mathrm{O}$ in the region near the hematite surface mainly caused by adsorption of carbonate species $\left(\mathrm{NaHCO}_{3}\right.$ buffer) or nitrate. In addition, smaller amounts of precipitated $\mathrm{K}$ and $\mathrm{Na}$ salts cannot be completely excluded in case of unwashed samples.

X-ray Absorption Spectroscopy (XAS) analysis was carried out on selected samples to identify the Se oxidation state as well as the type and nature of bonding environment between Se and the iron oxide phases. The examination of hematite and ferrihydrite samples from coprecipitation, adsorption and desorption studies allowed for a detailed characterization of the Se retention mechanisms and provided information on the identification of $\mathrm{Se}$ incorporation processes. Se K-edge X-ray Absorption Near-Edge Structure (XANES) and Extended X-ray Absorption Fine-Structure (EXAFS) spectra were partly collected at the SUL-X beamline at ANKA (Karlsruhe, Germany), but mainly at the Rossendorf Beamline (ROBL) at ESRF (Grenoble, France). The XAS measurement parameters are described in detail in the Supporting Information.

The evaluation of the XAS data, including dead time correction of the fluorescence signal, energy calibration and the averaging of single scans was performed with the software package SixPack. Normalization, transformation from energy into $\mathrm{k}$ space, and subtraction of a spline background was performed with WinXAS using routine procedures (Ressler, 1998). The $k^{3}$ weighted EXAFS data were fit with WinXAS using theoretical back-scattering amplitudes and phase shifts calculated with FEFF 8.2 (Ankudinov and Rehr, 1997). Statistical analysis of spectra was performed with the ITFA program package (Rossberg et al., 2003). Spectra of Se reference samples (crystalline $\mathrm{Na}_{2} \mathrm{SeO}_{4}$ and a $\mathrm{Se}(\mathrm{IV})$ solution) were taken from Scheinost and Charlet (2008).

\subsection{Data evaluation and error analysis}

Uptake of $\mathrm{Se}(\mathrm{IV})$ and $\mathrm{Se}(\mathrm{VI})$ by adsorption and coprecipitation was evaluated as proportion of the initial Se concentration (Se removal in \%) or in form of the distribution coefficients 
$\left(\mathrm{K}_{\mathrm{d}}\right.$ ), which considers the influence of the $\mathrm{m} / \mathrm{V}$ ratio between the solid mass (hematite) and the volume of the aqueous solution. The $\mathrm{K}_{\mathrm{d}}$-value $(\mathrm{L} / \mathrm{kg})$ is defined as

$$
\mathrm{K}_{\mathrm{d}}=\left(\frac{[\mathrm{Se}]_{0}}{[\mathrm{Se}]_{\mathrm{eq}}}-1\right) \cdot \frac{\mathrm{V}}{\mathrm{m}}
$$

where $[\mathrm{Se}]_{0}$ is the total initial Se concentration $(\mathrm{mol} / \mathrm{L}),[\mathrm{Se}]_{\mathrm{eq}}$ the aqueous Se concentration at equilibrium $(\mathrm{mol} / \mathrm{L}), \mathrm{V}$ the total volume $(\mathrm{L})$ of the aqueous solution and $\mathrm{m}$ the mass of hematite $(\mathrm{kg})$.

To verify the data quality and to assess the error, several experiments, each representing a single data point in the shown graphs, were performed two to three times under identical conditions. This included a repetition of the experiment as well as an individual sample preparation and analysis. All replicate experiments provided similar results and showed a high reproducibility.

\section{Results}

\subsection{Interaction of dissolved Se with hematite}

\subsubsection{Adsorption of Se(IV) and Se(VI) on hematite}

The hematite adsorption capacity for $\mathrm{Se}(\mathrm{IV})$ and $\mathrm{Se}(\mathrm{VI})$ as a function of $\mathrm{pH}$ is shown in Fig. 1. These results are an essential basis for the evaluation and interpretation of the $\mathrm{Se}$ coprecipitation data and demonstrate that $\mathrm{Se}(\mathrm{IV})$ and $\mathrm{Se}(\mathrm{VI})$ show a completely different adsorption behavior. Adsorption of Se(IV) is high over a large $\mathrm{pH}$ range (pH 2-9) and is even significant at alkaline conditions above $\mathrm{pH}$ 10. In contrast, $\mathrm{Se}(\mathrm{VI})$ adsorption onto hematite only takes place at acidic $\mathrm{pH}$ and strongly decreases with increasing $\mathrm{pH}$. Furthermore, variation of the ionic strength has no impact on Se(IV) adsorption, whereas the adsorption edge of $\mathrm{Se}(\mathrm{VI})$ is clearly shifted towards lower $\mathrm{pH}$ values (approx. $1 \mathrm{pH}$ unit) in the presence of higher concentrations of competing $\mathrm{NO}_{3}^{-}$anions. Fig. 1 also presents data $\left(\mathrm{K}_{\mathrm{d}}\right)$ of $\mathrm{Se}(\mathrm{IV})$ and $\mathrm{Se}(\mathrm{VI})$ adsorption onto hematite as a function of the Se equilibrium concentration at $\mathrm{pH}$ 7.5. Similar to the data of the $\mathrm{pH}$ study, the results indicate that adsorption of $\mathrm{Se}(\mathrm{IV})$ is not affected by increasing ionic strength. In the logarithmic plot, $K_{d}$ values of both $\mathrm{Se}(\mathrm{IV})$ data sets follow a decreasing linear trend with increasing Se concentrations in the solution. However, the absolute $K_{d}$ values are very high even at extremely high Se equilibrium concentrations and the Se surface coverage increases from 0.5 to $2.5 \mathrm{at} / \mathrm{nm}^{2}$. In contrast, 
$\mathrm{Se}(\mathrm{VI})$ adsorption is only weakly pronounced at these conditions and in case of a high ionic strength almost non-existing. Although $\mathrm{Se}(\mathrm{VI})$ adsorption seems to be slightly higher as long as no competing anions are present, which can be explained by the shift of the adsorption edge in dependence of the ionic strength, the general $\mathrm{K}_{\mathrm{d}}$ level is still very low even at minimal Se equilibrium concentrations.

\subsubsection{Se(IV) and Se(VI) coprecipitation with hematite}

Determining the residual Se concentration in solution after the coprecipitation experiments allowed the quantification of the $\mathrm{Se}(\mathrm{IV})$ or $\mathrm{Se}(\mathrm{VI})$ uptake during the hematite formation. Fig. 2 shows a comparison of the Se uptake by coprecipitation and adsorption as a function of the Se equilibrium concentration at $\mathrm{pH}$ 7.5. Similar to the former adsorption results, $\mathrm{Se}(\mathrm{IV})$ and $\mathrm{Se}(\mathrm{VI})$ sorption during coprecipitation with hematite strongly depends on the $\mathrm{Se}$ speciation. The Se(IV) uptake by coprecipitation is extremely high and rises to values of more than $0.8 \mathrm{~mol} / \mathrm{kg}$, whereas the sorption of $\mathrm{Se}(\mathrm{VI})$ is limited over the entire concentration range $(<0.05 \mathrm{~mol} / \mathrm{kg})$, cf. Table 1. Regarding the distinction between Se coprecipitation and adsorption, it is not possible to see clear differences in case of the Se(VI) data, due to the extremely low $\mathrm{Se}(\mathrm{VI})$ sorption capacity of hematite at neutral $\mathrm{pH}$ conditions. However, differences are clearly visible for the Se(IV) system in terms of a significantly higher Se uptake by coprecipitation than by adsorption. While adsorption of Se(IV) reaches an upper limit at $0.2-0.3 \mathrm{~mol} / \mathrm{kg}$, the $\mathrm{Se}$ (IV) uptake by coprecipitation increases steadily without indications of a sorption limit (at least up to the maximum initial Se(IV) concentrations of $10^{-}$ $2 \mathrm{~mol} / \mathrm{L})$.

Due to this significantly higher Se(IV) uptake by coprecipitation than by adsorption, it can be concluded that the retention of Se(IV) during coprecipitation with hematite cannot be exclusively ascribed to adsorption processes. Therefore, the observed difference in the uptake behavior of adsorption and coprecipitation experiments indicates that both processes are based on different sorption mechanisms.

\subsubsection{Se(IV) and Se(VI) desorption}

In a first approach, the reversibility of Se uptake in the adsorption and coprecipitation samples was investigated by taking advantage of the low adsorption capacity of hematite at $\mathrm{pH} 12$ (Fig. 1). Therefore, hematite samples from the Se adsorption and coprecipitation experiments, which were performed at 2 different initial Se concentrations of $10^{-4} \mathrm{~mol} / \mathrm{L}$ and $10^{-3} \mathrm{~mol} / \mathrm{L}$, were treated with a desorption solution of $\mathrm{pH} 12$ and the fraction of desorbed Se was 
determined by analyzing the amount of released Se (Fig. 3). The results show the known different behavior of $\mathrm{Se}(\mathrm{IV})$ and $\mathrm{Se}(\mathrm{VI})$ during the sorption step (bar heights), but also reveal that for both $\mathrm{Se}(\mathrm{IV})$ and $\mathrm{Se}(\mathrm{VI})$ the amount of desorbed Se is significantly higher for the adsorption in contrast to the coprecipitation samples (Fig. 3 left). This behavior is also observed for the higher Se loading (Fig. 3 right). For all adsorption samples, the treatment with the desorption solution causes the release of most of the adsorbed $\mathrm{Se}(\mathrm{IV})$ or $\mathrm{Se}$ (VI). In case of $\mathrm{Se}(\mathrm{IV})$, the release is equivalent to the hematite adsorption capacity at $\mathrm{pH} 12$ (desorption of $80-90 \%$ ), indicating that the Se(IV) uptake by adsorption is totally reversible; at least for samples with lower Se surface coverages $\left(\leq 1 \mathrm{at} / \mathrm{nm}^{2}\right)$. Compared with this, less than $30 \%$ of the taken up Se(IV) or $\mathrm{Se}(\mathrm{VI})$ is desorbed in case of the coprecipitated hematite samples.

The effect of $\mathrm{OH}^{-}$concentration (or $\mathrm{pH}$ ) on the stability of the Se retention was examined in detail for selected coprecipitation and adsorption samples of the Se(IV) system, as these samples showed major differences in their behavior not only in the desorption experiment but also during the actual Se sorption step. Fig. 4 shows the results of this study, which contains, beside different types of $\mathrm{Se}(\mathrm{IV})$-bearing hematite samples, also a sample of a $\mathrm{Se}(\mathrm{IV})$ coprecipitation with the hematite precursor ferrihydrite. In general, these results confirm the previous observation that the desorption behavior between coprecipitated and adsorbed hematite samples is completely different. Although the first release of $\mathrm{Se}(\mathrm{IV})$ starts at comparable $\mathrm{OH}^{-}$concentrations of about $10^{-4} \mathrm{~mol} / \mathrm{L}(\approx \mathrm{pH} 10)$ for both types of sorption processes, the proportion of desorbed Se(IV) increases rapidly for the adsorbed hematite samples and reaches a total amount of about $80 \%$ at the highest $\mathrm{OH}^{-}$concentration of $0.5 \mathrm{~mol} / \mathrm{L}(\approx \mathrm{pH} 13.7)$. In contrast, the coprecipitated hematite samples show a slow increase of the desorbed Se fraction with an overall proportion of only about $20 \%$ at the final stage. This is consistent with the results of the previous leaching studies at $\mathrm{pH} 12$, particularly considering the 3-fold desorption in those experiments. Furthermore, the comparison between ferrihydrite and hematite reveals that the desorption behavior of ferrihydrite is similar to that of the hematite adsorption samples. However, a comparison of the total Se and Fe release (Fig. A.4 in Supporting Information) demonstrates that $\mathrm{OH}^{-}$concentrations of $0.5 \mathrm{~mol} / \mathrm{L}$ are too low to dissolve significant amounts of the hematite phase $\left([\mathrm{Fe}]_{\text {released }} /[\mathrm{Fe}]_{\text {total }} \max .2 \cdot 10^{-3}\right)$.

\subsection{Interaction of Se with the precursor ferrihydrite}

Poorly crystalline 2-line ferrihydrite occurs as a metastable precursor of hematite that immediately precipitates from solution after the first increase of $\mathrm{pH}$ by adding $\mathrm{KOH}$ to the 
dissolved $\mathrm{Fe}^{3+}$. Subsequently, the ferrihydrite phase progressively transforms into well crystalline hematite during the total reaction period of 10 days. The progress of this transformation process can be identified in the XRD plot by the time-dependent disappearance of the 2 broad ferrihydrite peaks with maxima at $2 \theta$ of $\sim 35^{\circ}$ and $\sim 62^{\circ}$, which are associated with 2-line ferrihydrite (Fig. 5). Three selected Se(IV) coprecipitation samples show that the broad ferrihydrite peaks are visible in addition to the much stronger hematite lines after one and four days, while they have disappeared almost completely after 10 days and primarily those of hematite are left. Note also the presence of precipitated background electrolyte $\mathrm{KNO}_{3}$ in all analyzed samples because of the sample drying without prior washing of the suspensions.

Fig. 6 shows the temporal evolution of the Se(IV) or Se(VI) concentrations in solution during the formation and transformation of ferrihydrite. In case of Se(IV), the fast precipitation of ferrihydrite leads to an immediate Se removal from solution. After titration to $\mathrm{pH} 7.5$ (formation step 4) almost the entire initial Se amount is removed from solution, without any further changes within the subsequent 10 days during the ferrihydrite to hematite transformation. The behavior of $\mathrm{Se}(\mathrm{VI})$ is very different in so far as Se is removed from solution to below $20 \%$ only at the time of the first ferrihydrite precipitation (formation step 2.), but then solution concentration of $\operatorname{Se}(\mathrm{VI})$ increases rapidly to its final value of more than $90 \%$, where it remains unchanged for 10 days.

\subsection{Effect of the Se concentration on the type of Fe precipitates}

Table 1 compiles the main properties of some selected synthesized iron oxide samples from coprecipitation experiments with different initial Se concentrations. The data show that the proportion of sorbed $\mathrm{Se}$ is low for all coprecipitation samples of the $\mathrm{Se}(\mathrm{VI})$ system, but also that the presence of even extremely high $\mathrm{Se}(\mathrm{VI})$ concentrations has no effect on the formation of pure hematite and on the final $\mathrm{pH}$. In the Se(IV) system, however, the coprecipitation causes a high Se retention, while at the same time higher concentrations of dissolved Se(IV) lead to an incomplete formation of hematite and instead to hematite-goethite mixed phases (Fig. A.2 in Supporting Information). In addition, high initial Se(IV) amounts cause an increase of the solution $\mathrm{pH}$. This effect is visible at initial Se concentrations of more than $10^{-3}$ $\mathrm{mol} / \mathrm{L}$, and thus only when a certain $\mathrm{Se} / \mathrm{Fe}$ ratio, or a certain $\mathrm{Se}$ content of the iron oxide phase, are exceeded. For the type of hematite synthesized in this study, this specific Se content is in the range of about $0.7-1.3 \mathrm{wt} \%$. In contrast, the examination on ferrihydrite 
samples provide no evidence that a presence of higher amounts of Se(IV) affect the purity or composition of formed ferrihydrite.

Samples of the $\mathrm{Se}(\mathrm{VI})$ ferrihydrite system, on the other hand, show a behavior that is largely in accordance with the Se retention of the hematite system. At neutral $\mathrm{pH}$ conditions, the sorption of ferrihydrite for $\mathrm{Se}(\mathrm{VI})$ is also clearly limited compared to the retention capacity for Se(IV), but the interaction does not affect the solid phases. 
Table 1. Equilibrium (residual) concentrations of $\mathrm{Fe}$ and Se, the resulting Se removal (in \% and log $\mathrm{K}_{\mathrm{d}}$ ) and the mineral composition ( $\mathrm{Hm}$ : hematite, Gt: goethite, Fh: ferrihydrite) of selected samples of coprecipitation experiments with different initial amounts of Se; "X" $c(S e)_{0}=" X " \cdot 10^{-3} \mathrm{~mol} / \mathrm{L}$.

\begin{tabular}{|c|c|c|c|c|c|c|c|c|c|c|}
\hline \# & Se species & Sample & Mineral(s) ${ }^{a}$ & $\begin{array}{c}\mathrm{Se}^{b} \\
{[\mathrm{ppm}]}\end{array}$ & $\mathbf{p H}^{c}$ & $\begin{array}{l}\mathrm{c}(\mathrm{Fe})_{\text {eq }} \\
{[\mathrm{mol} / \mathrm{L}]}\end{array}$ & $\begin{array}{r}c(\mathrm{Se})_{0} \\
{[\mathrm{~mol} / \mathrm{L}]}\end{array}$ & $\begin{array}{l}\mathrm{c}(\mathrm{Se})_{\mathrm{eq}} \\
{[\mathrm{mol} / \mathrm{L}]}\end{array}$ & $\begin{array}{r}\text { Se sorbed } \\
{[\%]}\end{array}$ & $\begin{array}{l}\log K_{d} \\
{[L / k g]}\end{array}$ \\
\hline 1 & --- & $\mathrm{Hm}$ (pure) & $\mathrm{Hm}$ & bdl & 7.3 & $1.44 \mathrm{E}-07$ & 0.00 & bdl & --- & --- \\
\hline 2 & $\mathrm{Se}(\mathrm{VI})$ & $\mathrm{Se}(\mathrm{VI}) \mathrm{CopHm} \mathrm{m}^{0.1}$ & $\mathrm{Hm}$ & 34 & 7.6 & $1.33 \mathrm{E}-07$ & $1.02 \mathrm{E}-04$ & $8.66 \mathrm{E}-05$ & 15.3 & 1.30 \\
\hline 3 & $"$ & $\mathrm{Se}(\mathrm{VI}) \mathrm{CopHm}{ }^{1}$ & $\mathrm{Hm}$ & 280 & 7.3 & $8.74 \mathrm{E}-08$ & $1.02 \mathrm{E}-03$ & 8.97E-04 & 12.3 & 1.19 \\
\hline 4 & $"$ & $\mathrm{Se}(\mathrm{VI}) \mathrm{CopHm}{ }^{2}$ & $\mathrm{Hm}$ & 190 & 7.7 & 2.09E-07 & $2.04 \mathrm{E}-03$ & $1.80 \mathrm{E}-03$ & 11.9 & 1.17 \\
\hline 5 & $"$ & $\mathrm{Se}(\mathrm{VI}) \mathrm{CopHm}^{4}$ & $\mathrm{Hm}$ & 480 & 7.4 & $1.78 \mathrm{E}-05$ & $4.09 \mathrm{E}-03$ & $4.05 \mathrm{E}-03$ & 0.9 & 0.02 \\
\hline 6 & $"$ & $\mathrm{Se}(\mathrm{VI}) \mathrm{CopHm}{ }^{6}$ & $\mathrm{Hm}$ & 760 & 7.3 & 3.32E-05 & $6.13 E-03$ & $6.13 E-03$ & 0.0 & -- \\
\hline 7 & $"$ & $\mathrm{Se}(\mathrm{VI}) \mathrm{CopHm}{ }^{8}$ & $\mathrm{Hm}$ & 1100 & 7.3 & $3.38 \mathrm{E}-06$ & $8.18 \mathrm{E}-03$ & 8.07E-03 & 1.2 & 0.14 \\
\hline 8 & $"$ & $\mathrm{Se}(\mathrm{VI}) \mathrm{CopHm}{ }^{10}$ & $\mathrm{Hm}$ & 1600 & 7.7 & $1.25 \mathrm{E}-05$ & $1.02 \mathrm{E}-02$ & $1.01 \mathrm{E}-02$ & 1.0 & 0.04 \\
\hline 9 & $\mathrm{Se}(\mathrm{IV})$ & $\mathrm{Se}(\mathrm{IV}) \mathrm{CopHm}^{0.1}$ & $\mathrm{Hm}$ & 770 & 7.7 & $6.16 \mathrm{E}-08$ & $1.00 \mathrm{E}-04$ & $1.07 \mathrm{E}-07$ & 99.9 & 5.01 \\
\hline 10 & $"$ & $\mathrm{Se}(\mathrm{IV}) \mathrm{CopHm}{ }^{1}$ & $\mathrm{Hm}$ & 6900 & 7.6 & $5.70 \mathrm{E}-07$ & $1.00 \mathrm{E}-03$ & 1.19E-06 & 99.9 & 4.97 \\
\hline 11 & $"$ & $\mathrm{Se}(\mathrm{IV}) \mathrm{CopHm}{ }^{2}$ & $\mathrm{Hm}+\mathrm{Gt}$ & 13000 & 7.9 & $7.99 \mathrm{E}-08$ & $2.01 \mathrm{E}-03$ & $8.41 \mathrm{E}-06$ & 99.6 & 4.42 \\
\hline 12 & $"$ & $\mathrm{Se}(\mathrm{IV}) \mathrm{CopHm}{ }^{4}$ & $\mathrm{Gt}+\mathrm{Hm}$ & 21000 & 8.5 & $2.59 \mathrm{E}-06$ & 4.02E-03 & 4.88E-04 & 87.9 & 2.90 \\
\hline 13 & $"$ & $\mathrm{Se}(\mathrm{IV}) \mathrm{CopHm} \mathrm{m}^{6}$ & $\mathrm{Gt}+\mathrm{Hm}$ & 35000 & 8.5 & 9.33E-06 & $6.02 \mathrm{E}-03$ & 1.05E-03 & 82.5 & 2.72 \\
\hline 14 & $"$ & $\mathrm{Se}(\mathrm{IV}) \mathrm{CopHm}{ }^{8}$ & $\mathrm{Gt}+\mathrm{Hm}$ & 39000 & 8.6 & $6.00 \mathrm{E}-06$ & 8.03E-03 & $1.78 \mathrm{E}-03$ & 77.9 & 2.59 \\
\hline 15 & $"$ & $\mathrm{Se}(\mathrm{IV}) \mathrm{CopHm} \mathrm{m}^{10}$ & $\mathrm{Gt}+\mathrm{Hm}$ & 50000 & 8.3 & $1.45 \mathrm{E}-05$ & $1.00 \mathrm{E}-02$ & $2.10 \mathrm{E}-03$ & 79.1 & 2.62 \\
\hline 16 & --- & Fh (pure) & $\mathrm{Fh}$ & bdl & 7.9 & 2.74E-06 & 0.00 & bdl & --- & --- \\
\hline 17 & $\mathrm{Se}(\mathrm{VI})$ & $\mathrm{Se}(\mathrm{VI}) \mathrm{CopFh}^{1}$ & $\mathrm{Fh}$ & 1500 & 7.6 & 1.19E-05 & $1.02 E-03$ & $9.31 \mathrm{E}-04$ & 8.9 & 4.34 \\
\hline 18 & $"$ & $\mathrm{Se}(\mathrm{VI}) \mathrm{CopFh}^{4}$ & $\mathrm{Fh}$ & 6200 & 7.9 & 7.21E-06 & 4.09E-03 & 3.86E-03 & 5.5 & 1.04 \\
\hline 19 & $\mathrm{Se}(\mathrm{IV})$ & $\mathrm{Se}(\mathrm{IV}) \mathrm{CopFh}^{1}$ & $\mathrm{Fh}$ & 6200 & 8.1 & 7.42E-06 & $1.00 \mathrm{E}-03$ & 5.07E-06 & 99.5 & 4.23 \\
\hline 20 & $"$ & $\mathrm{Se}(\mathrm{IV}) \mathrm{CopFh}^{4}$ & $\mathrm{Fh}$ & 23000 & 8.1 & $3.72 \mathrm{E}-06$ & $4.02 \mathrm{E}-03$ & 2.57E-05 & 99.4 & 0.81 \\
\hline
\end{tabular}

To what extent the interaction with Se affects the mineral formation can also be seen in SEM images of coprecipitated samples (Fig. 7). For initial Se amounts of $4 \cdot 10^{-3} \mathrm{~mol} / \mathrm{L}$, it is clearly visible that coprecipitation with $\mathrm{Se}(\mathrm{VI})$ produces only pure hematite (Fig. 7a), whereas coprecipitation with Se(IV) causes the formation of a goethite-hematite mixed phase (Fig. 7c). Furthermore, SEM analyses of comparable hematite adsorption samples indicate that neither adsorption of $\mathrm{Se}(\mathrm{VI})$ nor $\mathrm{Se}(\mathrm{IV})$ has an influence on the hematite phase (Fig. 7b,d). This behavior was also verified by XRD results of hematite samples from adsorption studies (Supporting Information - Fig. A.3).

\subsection{Spectroscopic analyses of Se-bearing hematite and ferrihydrite samples}

XPS and XANES analysis were performed to identify the Se oxidation state on the mineral surface and within the bulk of Se-bearing hematite and/or ferrihydrite samples. The Se binding energies determined by XPS show that neither adsorption nor coprecipitation affects the original Se oxidation state (Supporting Information - Table A.1). In the same way, the analysis of the white line positions of collected Se K-edge XANES spectra indicate that the 
Se oxidation state remained unaltered by the reaction with hematite or ferrihydrite. For all iron oxide samples within the same Se system, the position of the absorption edge exactly matches the white line positions of $\mathrm{Se}(\mathrm{VI})$ or $\mathrm{Se}(\mathrm{IV})$ reference spectra $\left(\mathrm{Na}_{2} \mathrm{SeO}_{4}: 12.663 \mathrm{keV}\right.$, Se(IV) ref. solution: $12.660 \mathrm{keV}$ ) (Fig. 8).

Table 2. Se-K XANES edge energies and EXAFS fit results of hematite and ferrihydrite samples $\left(\mathrm{S}_{0}^{2}=0.9\right)$.

\begin{tabular}{|c|c|c|c|c|c|c|c|c|c|c|c|c|}
\hline \multirow[b]{2}{*}{ Sample } & \multirow[b]{2}{*}{$E_{0}[\mathrm{keV}]$} & \multicolumn{4}{|c|}{ oxygen shell } & \multicolumn{4}{|c|}{ iron shells } & & \multirow[b]{2}{*}{$\Delta \mathrm{E}_{0}[\mathrm{eV}]$} & \multirow[b]{2}{*}{$\mathrm{X}_{\text {res }}[\%]$} \\
\hline & & \multicolumn{2}{|c|}{$\mathrm{CN}^{a}$} & \multirow{2}{*}{$\begin{array}{r}\mathbf{R}[\AA]^{b} \\
1.65\end{array}$} & \multirow{2}{*}{$\frac{\sigma^{2}\left[\AA^{2}\right]^{c}}{0.0020}$} & \multirow[t]{2}{*}{ CN } & \multicolumn{2}{|r|}{$R[\AA ̊]$} & \multicolumn{2}{|l|}{$\sigma^{2}\left[\AA^{2}\right]$} & & \\
\hline $\mathrm{Se}(\mathrm{VI}) \mathrm{CopHm}^{10}$ & 12.6629 & 3.3 & 0 & & & & & & & & 14.5 & 8.1 \\
\hline $\mathrm{Se}(\mathrm{VI}) \mathrm{CopFh}^{4}$ & 12.6632 & 3.6 & $\mathrm{O}$ & 1.65 & 0.0009 & & & & & & 14.8 & 8.2 \\
\hline $\mathrm{Se}(\mathrm{VI}) \mathrm{AdsH} \mathrm{m}^{8}$ & 12.6633 & 3.6 & $\mathrm{O}$ & 1.65 & 0.0013 & & & & & & 14.4 & 9.3 \\
\hline $\mathrm{Se}(\mathrm{VI}) \mathrm{AdsHm}^{4}$ & 12.6632 & 3.6 & 0 & 1.66 & 0.0004 & & & & & & 15.5 & 9.5 \\
\hline $\mathrm{Se}(\mathrm{VI}) \mathrm{AdsHm}{ }^{1}-\mathrm{pH} 4$ & 12.6632 & 3.8 & $\mathrm{O}$ & 1.65 & 0.0010 & & & & & & 14.8 & 8.0 \\
\hline \multirow[t]{2}{*}{$\mathrm{Se}(\mathrm{IV}) \mathrm{CopHm}{ }^{1}$} & 12.6597 & 2.9 & 0 & 1.71 & 0.0015 & 0.7 & $\mathrm{Fe}$ & 2.94 & 0.0097 & $\#$ & 15.2 & 13.8 \\
\hline & & & & & & 2.5 & $\mathrm{Fe}$ & 3.43 & 0.0097 & $\#$ & & \\
\hline \multirow[t]{2}{*}{$\mathrm{Se}(\mathrm{IV}) \mathrm{CopHm}{ }^{1}$} & 12.6596 & 3.0 & 0 & 1.71 & 0.0015 & 0.5 & $\mathrm{Fe}$ & 2.95 & 0.0100 & $\#, \S$ & 15.8 & 14.1 \\
\hline & & & & & & 2.4 & $\mathrm{Fe}$ & 3.41 & 0.0100 & $\#, \S$ & & \\
\hline \multirow[t]{2}{*}{$\mathrm{Se}(\mathrm{IV}) \mathrm{CopHm}{ }^{1}$-DeSo } & 12.6595 & 3.0 & 0 & 1.71 & 0.0014 & 0.9 & $\mathrm{Fe}$ & 2.98 & 0.0100 & $\#, \S$ & 15.5 & 13.9 \\
\hline & & & & & & 2.8 & $\mathrm{Fe}$ & 3.43 & 0.0100 & $\#, \S$ & & \\
\hline \multirow[t]{2}{*}{$\mathrm{Se}(\mathrm{IV}) \mathrm{CopFh}^{1}$} & 12.6595 & 2.9 & 0 & 1.70 & 0.0014 & 0.3 & $\mathrm{Fe}$ & 2.89 & 0.0100 & $\#, \S$ & 15.3 & 14.4 \\
\hline & & & & & & 1.4 & $\mathrm{Fe}$ & 3.34 & 0.0100 & $\#, \S$ & & \\
\hline \multirow[t]{2}{*}{$\mathrm{Se}(\mathrm{IV}) \mathrm{CopFh}^{4}$} & 12.6595 & 2.8 & 0 & 1.71 & 0.0013 & 0.3 & $\mathrm{Fe}$ & 2.88 & 0.0072 & $\#$ & 15.6 & 12.8 \\
\hline & & & & & & 1.1 & $\mathrm{Fe}$ & 3.34 & 0.0072 & $\#$ & & \\
\hline \multirow[t]{2}{*}{$\mathrm{Se}(\mathrm{IV}) \mathrm{AdsHm}{ }^{1}$} & 12.6596 & 2.9 & 0 & 1.71 & 0.0016 & 0.3 & $\mathrm{Fe}$ & 2.90 & 0.0056 & $\#$ & 15.5 & 13.1 \\
\hline & & & & & & 1.6 & $\mathrm{Fe}$ & 3.38 & 0.0056 & \# & & \\
\hline \multirow[t]{2}{*}{$\mathrm{Se}(\mathrm{IV}) \mathrm{AdsHm}{ }^{4}$} & 12.6598 & 2.9 & 0 & 1.70 & 0.0018 & 0.3 & $\mathrm{Fe}$ & 2.89 & 0.0049 & $\#$ & 15.1 & 12.1 \\
\hline & & & & & & 1.3 & $\mathrm{Fe}$ & 3.37 & 0.0049 & \# & & \\
\hline \multirow[t]{2}{*}{$\mathrm{Se}(\mathrm{IV}) \mathrm{AdsHm} \mathrm{H}^{1} \mathrm{pH} 4$} & 12.6594 & 2.7 & & & 0.0011 & 0.4 & $\mathrm{Fe}$ & 2.91 & 0.0030 & $\#$ & 15.5 & 12.8 \\
\hline & & & & & & 0.8 & $\mathrm{Fe}$ & 3.38 & 0.0030 & \# & & \\
\hline
\end{tabular}

${ }^{a} \mathrm{CN}$ : coordination number, error $\pm 25 \% .{ }^{b} \mathrm{R}$ : Radial distance, error $\pm 0.01 \AA^{\circ}{ }^{c} \sigma^{2}$ : Debye-Waller factor, error $\pm 0.0005 \AA^{2}$.

" correlated $\sigma^{2}{ }^{\S}{ }^{\S}$ Upper $\sigma^{2}$ limit reached. " ${ }^{\prime \prime} \mathrm{c}(\mathrm{Se})_{0}=$ "X" $\cdot 10^{-3} \mathrm{~mol} / \mathrm{L}$. "DeSo": Sample from desorption study.

In order to characterize the Se retention mechanisms in detail, samples of each system with different natures of Se sorption - partly more than one of the same type - were analyzed by Se K-edge EXAFS spectroscopy (Fig. 8). The $\mathrm{k}^{3}$-weighted $\chi$ spectra were fit with a FEFF 8.2 file that was generated with the crystallographic structure of mandarinoite $\left(\mathrm{Fe}_{2}\left(\mathrm{SeO}_{3}\right)_{3} \cdot 6 \mathrm{H}_{2} \mathrm{O}\right.$, CIF 0005198, Hawthorne, 1984). For all samples of the Se(VI) system, the EXAFS Fourier transform magnitude is dominated by only one strong peak at $1.3 \AA$ (uncorrected for phase shift). A fit of this peak with a single scattering Se-O path lead to oxygen coordination numbers $(\mathrm{CN})$ of $3.3-3.8$ and to atomic distances of $1.65 \AA$ (Table 2), confirming the unchanged hexavalent oxidation state and the tetrahedral structure of the $\mathrm{Se}(\mathrm{VI})$ anion. Apart from that, no additional peaks are visible and thus no signs of further shells beyond the oxygen coordination sphere. For the samples of the Se(IV) system, the EXAFS Fourier transform show the oxygen coordination shell at about $1.4 \AA$ (uncorrected for phase shift, Fig. 8). A fit of those peaks result in coordination numbers of $2.7-3.0$ and atomic distances 
of 1.70 - $1.71 \AA$ (Table 2), confirming the tetravalent Se oxidation state and the unchanged pyramidal-shaped molecular structure of Se(IV) (Chen et al., 1999).

In contrast to the Se(VI) system, the Fourier transform of the EXAFS spectra of $\mathrm{Se}(\mathrm{IV})$ samples show further structural features beyond the oxygen coordination shell. Two peaks that appear close to each other rise above the background in the range at $2.5-3.0 \AA$ (uncorrected for phase shift), whereby the signal intensity, the form and the distances of those peaks differ in dependency of the sample origin and the associated Se sorption type. Two individual single scattering Se-Fe paths were used to achieve a good fitting of those peaks (Table 2), whereas the use of only one Se-Fe path or a mixture of $\mathrm{Se}-\mathrm{Fe}$ and $\mathrm{Se}-\mathrm{O}$ paths led to poor results. Note that the Debye-Waller factors of both Se-Fe paths were kept correlated to obtain stable fit results.

\section{Discussion}

\subsection{Adsorption data}

The observed Se adsorption behavior is consistent with data of previous studies by Duc et al. (2006) and Rovira et al. (2008) and suggest that adsorption of Se(IV) onto hematite can be attributed to a specific adsorption and the formation of inner-sphere surface complexes. With maximum values of up to $2.5 \mathrm{at} / \mathrm{nm}^{2}$, the determined Se surface coverage is in line with other $\mathrm{Se}(\mathrm{IV})$ adsorption studies on hematite or goethite (Su and Suarez, 2000; Duc et al., 2003; Rovira et al., 2008). These authors also reported of Se surface coverages in the range of $\sim 2$ $\mathrm{at} / \mathrm{nm}^{2}$ or higher and they attributed this Se uptake to the formation of different types of innersphere Se(IV) complexes. However, even though there is no direct evidence for separate Se mineral phases, one cannot fully exclude the possibility of a Se surface precipitation, particularly in case of hematite samples that are characterized by high Se surface coverages.

Furthermore, the low $\mathrm{Se}(\mathrm{VI})$ adsorption to hematite and the strong negative impact of an increasing $\mathrm{pH}$ and ionic strength is in agreement with data of $\mathrm{Se}(\mathrm{VI})$ adsorption studies on other ferric oxide minerals (Su and Suarez, 2000; Rietra et al., 2001; Wijnja and Schulthess, 2002; Duc et al., 2003; Das et al., 2013).

\subsection{Stability of the Se retention}

Based on the results of the desorption studies, it can be concluded that Se retention by coprecipitation with hematite is not only the predominant but also the more stable immobilization process compared to adsorption. However, since it was not possible to 
dissolve larger amounts of the hematite phase with maximum $\mathrm{OH}^{-}$concentrations of $0.5 \mathrm{~mol} / \mathrm{L}$ (Supporting Information - Fig. A.4), potentially incorporated Se should not be released in this kind of dissolution experiments. The desorption data can therefore neither confirm nor exclude the existence of a Se incorporation mechanism. Nonetheless, the similar desorption behavior of the ferrihydrite coprecipitation sample and the hematite adsorption samples suggests that the interaction between Se(IV) and ferrihydrite remains adsorption at the early stage of the coprecipitation process. This means that the mechanism, which is responsible for the higher stability of Se in the hematite coprecipitation samples, is definitely linked to the ferrihydrite recrystallization process. For this reason, the formation pathway of hematite must have a significant influence on the interaction between dissolved Se oxyanions and the forming iron oxide.

\subsection{Development and implications of the coprecipitation process}

The temporal development of the hematite formation (Fig. 5) demonstrates that the transformation of ferrihydrite into hematite lasts a few days, during which the dissolved Se oxyanions interact with the crystallizing phase. The early stages of this interaction process (Fig. 6), including the fast removal of $\mathrm{Se}(\mathrm{VI})$ by ferrihydrite at low $\mathrm{pH}$ (about 2) and the subsequent release with increasing $\mathrm{pH}$ is in line with the typical $\mathrm{pH}$ dependence of oxyanion outer-sphere sorption already documented in Fig. 1 (left). As tested in own preliminary studies and also described in the literature by several authors, Se shows a rapid adsorption kinetic on iron(III)-oxide minerals (Zhang and Sparks, 1990; Su and Suarez, 2000; Rovira et al., 2008; Mitchell et al., 2013). Again, this behavior suggests that the uptake of Se oxyanions in the coprecipitation experiments is different from adsorption and that the associated retention mechanism is related to the ferrihydrite/hematite recrystallization.

In addition, the main properties of the Fe precipitates (Table 1) illustrate that the presence of Se during the crystallization of hematite from ferrihydrite has not only an impact on the Se retention process but equally influences the transformation process of ferrihydrite into hematite. This latter point is, however, only detectable in case of an exceedance of a certain Se concentration threshold as well as a strong interaction between the dissolved Se and the ferrihydrite/hematite phase, which occurs only for Se(IV). The identified threshold of 0.7 $1.3 \mathrm{wt} \% \mathrm{Se}$ (or $\mathrm{c}(\mathrm{Se})_{0}=10^{-3}-2 \cdot 10^{-3} \mathrm{~mol} / \mathrm{L}$ ) is equivalent to a theoretical Se surface coverage of 1 - $2 \mathrm{at} / \mathrm{nm}^{2}$. This value also corresponds with the Se surface coverage at the point, where the adsorption capacity of hematite for Se(IV) starts to approach an upper limit and hematite is no longer able to remove all dissolved Se(IV) from solution (Fig. 2). 
However, one has to consider that in this context not the surface coverage of hematite but the unknown surface coverage of ferrihydrite, before the recrystallization to hematite or goethite, has to be the more relevant parameter. A similar inhibition of the ferrihydrite recrystallization by oxyanions species was reported, among others, by Gálvez et al. (1999a). There, a small amount of phosphate favored the transformation of ferrihydrite into hematite, whereas higher phosphate concentrations caused the formation of goethite. This behavior was attributed to the formation of inner-sphere adsorption complexes, which disturb the transformation of ferrihydrite into hematite due to the increasing negative surface charge at high phosphate concentrations. This is consistent with our data, where Se(IV) supposedly also interacts as an inner-sphere sorbed species with ferrihydrite or hematite.

\subsection{Characterization of the retention mechanisms}

Based on the results of the XPS analysis, it can be concluded that the interaction processes between dissolved Se(IV) and hematite cause no changes of the Se(IV) valency. This is also confirmed by the XAS data (Fig. 8), which show that the Se oxidation state remains unaffected by the interaction with hematite or ferrihydrite in case of both Se speciations.

For the $\mathrm{Se}(\mathrm{VI})$ system, the unchanged Se oxidation state, together with the absence of atomic neighbors beyond the oxygen coordination shell, indicates the presence of a hydration sphere and hence outer-sphere bonding of the $\mathrm{Se}(\mathrm{VI})$ species for all analyzed iron oxides (Fig. 10a). No indication for inner-sphere sorption or any evidence of incorporation was found. Concluding from a number of previous studies about $\mathrm{Se}(\mathrm{VI})$ adsorption on goethite, $\mathrm{Se}(\mathrm{VI})$ species are able to form both inner- and outer-sphere adsorption complexes depending on the respective conditions. While some authors solely identified inner-sphere $\mathrm{Se}(\mathrm{VI})$ complexes on goethite (Su and Suarez, 2000; Das et al., 2013), other publications demonstrated the formation of a mixture of inner- and outer-sphere adsorption complexes, whereby the distribution of both types strongly depends on parameters like $\mathrm{pH}$, ionic strength or the surface coverage (Peak and Sparks, 2002; Fukushi and Sverjensky, 2007). Especially the pH plays a key role in this context and leads, at least in case of goethite, to the formation of mainly inner-sphere complexes at $\mathrm{pH}$ values below 6 , whereas a higher $\mathrm{pH}$ causes the formation of primarily outer-sphere complexes (Wijnja and Schulthess, 2000; Rietra et al., 2001). In contrast, the interaction of $\mathrm{Se}(\mathrm{VI})$ with hematite and ferrihydrite is not so well studied and partly contradictory in terms of the nature of the $\mathrm{Se}(\mathrm{VI})$ complexes. According to Peak and Sparks (2002), the behavior of ferrihydrite should be similar to that of goethite, which is consistent with our results when taking into account the neutral $\mathrm{pH}$ conditions and 
the mentioned $\mathrm{pH}$ dependency. The hydrochemical conditions during the mineral synthesis are responsible for a relatively high ionic strength, which would favor inner-sphere sorption because of competition effects; however, this was not observed. Our results are hence in disagreement with those of Das et al. (2013), who clearly identified inner-sphere Se(VI) complexes on ferrihydrite at comparable neutral $\mathrm{pH}$ conditions, but at substantially lower ionic strengths. Published data of Se(VI) adsorption on hematite (Peak and Sparks, 2002) demonstrate an inner-sphere complexation, which is additionally unaffected by $\mathrm{pH}$. A possible reason for this difference could be the dominant anion in the used background electrolyte (here nitrate instead of chloride). While chloride is known to have one of the lowest adsorption affinities for iron oxides, the affinity of the oxyanion nitrate is higher and more comparable with selenate (Neal, 1995), hence nitrate most likely out-competes selenate at inner-sphere sorption sites.

In contrast to the $\mathrm{Se}(\mathrm{VI})$ system, the EXAFS data of Se(IV) samples are characterized by $2 \mathrm{Fe}$ shells in addition to the oxygen coordination sphere (Fig. 8). In general, the presence of Fe atoms in the second shell implies a direct linkage of the Se(IV) oxyanions to the iron oxide without an additional hydration sphere and thus a bonding of an inner-sphere nature (Fig. 10b). The fit results (Table 2), which include the first published EXAFS fittings of $\mathrm{Se}$ (IV) interaction with hematite, are in good agreement with published data of $\mathrm{Se}$ (IV) adsorption on other types of iron (oxyhydr)oxides, particularly in terms of the atomic $\mathrm{Fe}$ distances of $2.88-2.98 \AA$ for the shorter-distant and $3.34-3.43 \AA$ for the longer-distant Fe atoms. These distances suggest the formation of a bidentate mononuclear edge-sharing ${ }^{2} \mathrm{E}$ arrangement between the $\mathrm{SeO}_{3}^{2-}$ pyramidal molecule and the hematite $\mathrm{FeO}_{6}$ octahedra in case of the shorter-distant $\mathrm{Fe}$ atoms, while the longer-distant $\mathrm{Fe}$ shell represents bidentate binuclear corner-sharing ${ }^{2} \mathrm{C}$ complexes (Hayes et al., 1987; Manceau and Charlet, 1994; Hiemstra et al., 2007; Missana et al., 2009; Jordan et al., 2014). In case of Se(IV), the formation of ${ }^{2} \mathrm{E}$ and ${ }^{2} \mathrm{C}$ adsorption complexes does not cause structural features beyond distances of $3.5 \AA$, which was also demonstrated by other publications regarding these two types of $\mathrm{Se}(\mathrm{IV})$ complexes on iron oxide surfaces. ${ }^{2} \mathrm{E}$ and ${ }^{2} \mathrm{C}$ complexes occur in all investigated hematite and ferrihydrite samples at the same time, and were also observed for ferrihydrite (Manceau and Charlet, 1994), magnetite (Missana et al., 2009) and maghemite (Jordan et al., 2013; Jordan et al., 2014). The only iron oxyhydroxide mineral with different adsorption characteristics is goethite, for which, by EXAFS and IR spectrometry or surface complexation modeling, only corner-sharing ${ }^{2} \mathrm{C}$ complexes were identified (Hayes et al., 
1987; Su and Suarez, 2000; Hiemstra et al., 2007). The formation of corner- and edge-shared complexes on specific crystal surfaces and their proportions depends on $\mathrm{pH}$, crystal morphology, and the surface coverage (Manceau and Charlet, 1994; Hiemstra et al., 2007; Missana et al., 2009; Jordan et al., 2013; Jordan et al., 2014). Since higher coverages favor the formation of both corner- and edge-shared complexes (Hiemstra et al., 2007), this would explain why all investigated Se(IV)-bearing hematite and ferrihydrite samples show both types of surface complexes. Furthermore, the generally needle-shaped morphology of goethite and the related dominance of $\{110\}$ faces only allows the occurrence of ${ }^{2} \mathrm{C}$ complexes (Manceau and Charlet, 1994; Ona-Nguema et al., 2005). Hematite and ferrihydrite, in contrast, have a more versatile morphology and are characterized by crystal faces that enable a simultaneous formation of ${ }^{2} \mathrm{E}$ and ${ }^{2} \mathrm{C}$ adsorption complexes (Trainor et al., 2004; OnaNguema et al., 2005).

The key finding of the fitting is, however, that all hematite samples, for which both adsorption and other retention mechanisms are conceivable, show significantly higher coordination numbers and larger Se-Fe distances than the samples where various retention mechanisms are unlikely or can be ruled out by the sorption studies as shown above. This latter group includes hematite and ferrihydrite samples with only an adsorbed fraction of Se [Se(IV)AdsHm and $\mathrm{Se}(\mathrm{IV}) \mathrm{CopFh}$, which are all characterized by smaller coordination numbers and distances of $0.3-0.4$ at $2.88-2.91 \AA$ for the short-distant Fe atoms and of $0.8-1.6$ at $3.34-3.38 \AA$ for the far-distant $\mathrm{Fe}$ shell. These coordination numbers fit very well with the assumed adsorption model, consisting of a mixture of mononuclear edge-sharing and binuclear corner-sharing inner-sphere complexes (coexistence of different types of surface complexes inevitably leads to a reduction of the analyzed coordination numbers). In contrast, all hematite samples of coprecipitation experiments [Se(IV)CopHm], show larger coordination numbers and distances of $0.5-0.9$ at $2.94-2.98 \AA$ for the shorter-distant Fe atoms and $2.4-2.8$ at $3.41-3.43 \AA$ for the longer-distant $\mathrm{Fe}$ atoms. Compared to the adsorbed samples, these coordination numbers, with values clearly above 2.0 in case of the far-distant Fe atom, are too high to be explained by the formation of typical surface adsorption complexes.

In order to verify and, at best, confirm the different characteristics of Se coprecipitation and adsorption, a statistical analysis of the EXAFS spectra was performed using Iterative Transformation Factor Analysis (ITFA) (Rossberg et al., 2003; Scheinost and Charlet, 2008). Fig. 9 (left) shows the excellent match between the experimental spectra (black lines) and their reconstructions (red lines) by two principal components (PC). The Principal Component 
Analysis reveals therefore that two different Se sorption species or sorption mechanisms are needed to characterize the spectra of all Se(IV) samples. Furthermore, the Varimax factor loadings (Fig. 9, right) demonstrate that the Se(IV) adsorption samples are dominated by PC 2, while PC 1 is mainly present in the hematite samples of coprecipitation experiments. The latter is particularly true for the afterwards desorbed hematite sample [Se(IV)CopHmDeSo], which should be completely free from adsorbed Se. (Note that the other coprecipitation samples contain adsorbed Se oxyanions with a proportion of approx. $25 \%$; Fig. 3). The statistical analysis therefore confirms the previous interpretation of the fitting results in terms that the retention mechanisms for Se coprecipitation and adsorption are different.

One possible explanation for the EXAFS results of the coprecipitated hematite samples would be the formation of an independent solid $\mathrm{Se}$ and $\mathrm{Fe}$ hosting mineral phase. Missana et al. (2009) reported that under certain circumstances, especially low $\mathrm{pH}$ values, sorption of Se(IV) onto magnetite can induce the precipitation of ferric selenite $\left[\mathrm{Fe}_{2}\left(\mathrm{SeO}_{3}\right)_{3} \cdot 3 \mathrm{H}_{2} \mathrm{O}\right]$ as a crystalline species. In a similar way, Bolanz et al. (2013) demonstrated for As(V) that an interaction during the ferrihydrite-hematite recrystallization causes the formation of angelellite-like clusters $\left[\mathrm{Fe}_{4} \mathrm{As}_{2} \mathrm{O}_{11}\right]$, which are incorporated in the hematite phase as a separate structural composite. However, both mineral structures would produce characteristic structural features in EXAFS FT region beyond $3.5 \AA$ indicative of significant long-range order, which are absent in our samples. In addition, even in case of an amorphous or poorly crystalline $\mathrm{Se}$ and $\mathrm{Fe}$ containing mineral phase, one would expect to see distinctive coordination shells caused by the nearest iron neighbors. Ferric selenite minerals like $\mathrm{Fe}_{2}\left(\mathrm{SeO}_{3}\right)_{3} \cdot 3 \mathrm{H}_{2} \mathrm{O}$ or mandarionite $\left(\mathrm{Fe}_{2}\left(\mathrm{SeO}_{3}\right)_{3} \cdot 6 \mathrm{H}_{2} \mathrm{O}\right)$ are usually characterized by $3 \mathrm{Fe}$ neighbors at atomic distances in the range of $3.21-3.33 \AA$ (Hawthorne, 1984; Giester and Pertlik, 1994; Missana et al., 2009), a coordination shell that does not occur in any of the analyzed samples. The formation of an independent $\mathrm{Se}$ and $\mathrm{Fe}$ containing mineral phase (ferric selenite) can hence be excluded for the Se-bearing samples (surface coverages $\sim 1$ at $/ \mathrm{nm}^{2}$ ) that were used for detailed spectroscopic analyses.

An alternative, and the more likely, explanation for higher coordination numbers than the expected ones for adsorption complexes (in our case higher than 0.5 and 1.0, respectively, for a spectral mixture of ${ }^{2} \mathrm{E}$ and ${ }^{2} \mathrm{C}$ sorption complexes) are structural incorporation processes. However, the signal intensity and coordination numbers of the Fe are relatively low, and there is a lack of structural features beyond $3.5 \AA$ (for uncorrected phase shift), which is rather 
untypical for a structural incorporation (inclusion) based on substitution or the occupation of vacant sites. Moreover, such an incorporation of oxyanions into the hematite crystal lattice was proven practically only for $\mathrm{P}(\mathrm{V})$ (Gálvez et al., 1999b) and theoretically for Tc(VII) (Skomurski et al., 2010). Both $\mathrm{P}(\mathrm{V})$ and Tc(VII) have a tetrahedral structure and are coordinated by 4 oxygen atoms, which enables to occupy the tetrahedral vacancies within the hematite crystal structure. Since an occupation of the hematite tetrahedral or octahedral sites seems to be unrealistic in case of the pyramidal-shaped $\mathrm{Se}(\mathrm{IV})$, this indicates $\mathrm{Se}(\mathrm{IV})$ is incorporated in a different form. We assume that incorporation of Se can be attributed to originally adsorbed Se oxyanion surface complexes that are entrapped in the hematite bulk phase during the ferrihydrite-hematite recrystallization process (incorporated adsorption complexes). Incorporated $\mathrm{Se}(\mathrm{IV})$ is consequently bound to the hematite phase in a way that is similar to $\mathrm{Se}(\mathrm{IV})$ adsorption complexes, which are characterized by a direct linkage and a specific inner-sphere complexation $\left({ }^{2} \mathrm{E}\right.$ or ${ }^{2} \mathrm{C}$ complexes) between the $\mathrm{Se}(\mathrm{IV})$ molecules and the hematite (Fig. 10c). That the transformation of ferrihydrite into hematite can lead to an incorporation of originally adsorbed species is also mentioned in Das et al. (2015) for the oxyanion As(V). Similar to Se(IV) in this study, the authors demonstrated that As(V) was incorporated into newly formed hematite via both bidentate-mononuclear and binuclear corner sharing complexes. Another possible example for an analogous sorption mechanism was described by Scheinost et al. (2006) for $\mathrm{Sb}(\mathrm{V})$. In this case, EXAFS results provided indications of a comparable incorporation of $\mathrm{Sb}(\mathrm{V})$ into the structure of an iron oxide mineral. Just like $\mathrm{Se}(\mathrm{IV})$ in our results, this $\mathrm{Sb}(\mathrm{V})$ species showed two sorption complexes with associated coordination numbers that were larger than the expected ones of surface adsorption complexes, but were also too small to be explained by substitution or the occupation of vacancies.

However, even if the atomic Se-Fe distances are predetermined to a certain extent in the case of internal $\mathrm{Se}(\mathrm{IV})$ adsorption complexes, it cannot be unambiguously determined whether the additional neighboring atoms of the hematite phase are responsible for the observed increase of the number of Fe atoms or not. This is due to the fact that the local structure of the Se(IV)hematite network remains unclear and is likely to be highly variable. Moreover, the additional $\mathrm{Se}-\mathrm{O}$ and Se-Fe contributions should lead to increased Debye-Waller factors, which could not be verified, since the hematite samples with and without incorporated Se(IV) show similar Debye-Waller factors and both types of samples reach the prescribed upper limit in some cases. 
The hypothesis of a Se incorporation mechanism is also supported by the general behavior of $\mathrm{Se}(\mathrm{VI})$. Although it is not possible to directly verify incorporation of $\mathrm{Se}(\mathrm{VI})$ into hematite by EXAFS data, on the basis of the hydrochemical sorption results, it can, nevertheless, be assumed that also $\mathrm{Se}(\mathrm{VI})$ gets incorporated into hematite during the ferrihydrite transformation. Especially the $\mathrm{Se}(\mathrm{VI})$ behavior in the aquatic phase and the stability of the $\mathrm{Se}(\mathrm{VI})$ retention against subsequent desorption (Fig. 3) are clear signs for the presence of an incorporated Se(VI) fraction. However, since this incorporated Se(VI) fraction is, according to the EXAFS data, still bound in form of outer-sphere complexes, a corresponding $\mathrm{Se}(\mathrm{VI})$ incorporation process is definitely not associated with a change of the surface complexation type (Fig. 10c). This supports the previous findings of the Se(IV) data evaluation, that incorporation of Se oxyanions into hematite cannot be attributed to substitution or occupation of crystallographic sites within the hematite lattice.

\subsection{Conceptual model of the Se retention during the crystallization of hematite}

The combination of hydrochemical and spectroscopic data lead to the outcome that three individual interaction processes control the fate of dissolved $\mathrm{Se}$ oxyanions during coprecipitation with hematite via ferrihydrite. The first process is the fast coprecipitation of Se oxyanions with ferrihydrite. Due to the large specific surface area of ferrihydrite, high quantities of Se can be adsorbed on the surface. The different surface areas of poorly crystalline ferrihydrite and well crystalline hematite are the reason why the uptake of Se resulting from coprecipitation is potentially higher than the Se uptake by pure adsorption on hematite after a completed mineral formation. The first adsorption of Se on ferrihydrite therefore significantly defines the total amount of sorbed Se during the whole coprecipitation process. Since the ferrihydrite adsorption capacity for Se, like for all iron oxides, is strongly influenced by the Se speciation and the parameters $\mathrm{pH}$ and ionic strength, this interaction process is responsible for the much larger uptake of inner-sphere bound Se(IV) than of outersphere bound $\mathrm{Se}(\mathrm{VI})$, at least under the investigated conditions.

The second interaction process represents the incorporation of Se during the transformation of unstable ferrihydrite into crystalline hematite. Compared to the previous Se adsorption onto ferrihydrite, the Se incorporation is less critical for the amount of sorbed Se, but is crucial for the stability of the Se retention, since the majority of adsorbed Se oxyanions are incorporated into the hematite during its crystallization. Coprecipitated Se, with a high fraction of incorporated $\mathrm{Se}$, is thus more stable against a subsequent desorption than solely adsorbed Se 
oxyanions. In case of high Se concentrations and high adsorption, i.e. under neutral or alkaline $\mathrm{pH}$ conditions and for Se(IV), the surface coverage of ferrihydrite can become so high that the adsorbed Se complexes prevent a complete transformation of ferrihydrite into hematite. In this case, the transformation of ferrihydrite in hematite, which involves internal dehydration and rearrangement processes (Adegoke et al., 2013), seems to be no longer possible. Instead, the ferrihydrite transforms via dissolution and precipitation that causes the formation of goethite instead of hematite.

The last process is the adjustment of an adsorption/desorption equilibrium between the formed hematite and all dissolved water components in the aquatic phase. The equilibrium between dissolved and adsorbed Se oxyanions is influenced by the prevailing hydrochemical conditions, the presence of competing anions and the hematite properties, as these parameters determine the type of possible Se adsorption complexes. However, due to the previous Se incorporation during the hematite crystallization, most of the Se is, at that point, no longer in direct contact with the aquatic phase. The adsorption/desorption processes therefore affect only the retention behavior and stability of the smaller adsorbed Se fraction, but not the fraction of incorporated Se.

\section{Conclusion}

This study has demonstrated that during the crystallization of hematite from ferrihydrite under natural conditions, interacting Se oxyanions are not adsorbed but mainly incorporated into hematite. This incorporation process follows the previous adsorption of Se oxyanions onto ferrihydrite, the primarily precipitated iron oxide phase, and takes place during the subsequent transformation of amorphous ferrihydrite into crystalline hematite. The proportion of incorporated Se is largely defined by the adsorption capacity of ferrihydrite for $\mathrm{Se}(\mathrm{IV})$ and $\mathrm{Se}(\mathrm{VI})$ under the prevailing conditions prior to the crystallization process. The incorporation mechanism itself results from a direct linkage between the Se oxyanions and the hematite phase, but is not attributed to substitution or occupation of crystallographic sites within the hematite crystal lattice. This is why the incorporated Se oxyanion species are bound to the hematite phase in a way that is similar to surface adsorption complexes - outer-sphere complexes for Se(VI) and inner-sphere complexes for Se(IV). Compared to adsorbed Se oxyanions, the retention of the incorporated Se fraction is very resistant even at alkaline $\mathrm{pH}$ conditions at least as long as the hematite mineral remains stable. 
These results provide new knowledge about the retention behavior of Se oxyanions in natural environments. This concerns all places where iron oxides are newly formed or mineral transformation processes take place, including, for instance, the oxidized, near-surface regions of contaminated areas or within the critical zone. In all these environments, incorporation of Se oxyanions into iron oxides, and specifically hematite, can represent a main long-term immobilization mechanism. This may be important for mobility assessments of Se oxyanions or could be applied for the treatment of polluted wastewaters.

\section{Acknowledgments}

This work is part of the IMMORAD project, funded by the German Federal Ministry for Education and Research (BMBF) under grant No. 02NUK019B. Additional financial support was provided by the Graduate School for Climate and Environment (GRACE) at KIT. The authors would like to thank Volker Zibat for SEM analysis, Dr. Peter Weidler for BET determination and Dr. Jörg-Detlef Eckhardt for assistance with XRD analysis. We also thank Dr. Utz Kramar and Claudia Mößner for their help during XRF and ICP-MS analysis. We acknowledge ANKA for providing beam time and thank Dr. Jörg Göttlicher and Dr. Ralph Steininger for assistance at the SUL-X beamline. The ESRF and the team of the Rossendorf Beamline (BM 20) are gratefully acknowledged for the provision of beam time and their support during the XAS measurements. Finally, we would like to thank the associate editor, Christophe Tournassat, and three anonymous reviewers for their constructive and helpful comments to improve the manuscript.

\section{References}

Adams D. J. and Pickett T. M. (1998) Microbial and cell-free selenium bioreduction in mining waters. In Environmental Chemistry of Selenium (eds. W. T. Frankenberger and R. A. Engberg). Marcel Dekker, New York, USA. pp. 479-499.

Adegoke H. I., Adekola F. A., Fatoki O. S. and Ximba B. J. (2013) Sorptive interaction of oxyanions with iron oxides: A Review. Polish J. Environ. Stud. 22, 7-24.

Ankudinov A. L. and Rehr J. J. (1997) Relativistic calculations of spin-dependent x-ray-absorption spectra. Phys. Rev. B 56, 1712-1715.

Bajaj M., Eiche E., Neumann T., Winter J. and Gallert C. (2011) Hazardous concentrations of selenium in soil and groundwater in North-West India. J. Hazard. Mater. 189, 640-646.

Balistrieri L. S. and Chao T. T. (1990) Adsorption of selenium by amorphous iron oxyhydroxide and manganese dioxide. Geochim. Cosmochim. Acta 54, 739-751.

Blume H.-P., Brümmer G. W., Fleige H., Horn R., Kandeler E., Kögel-Knabner I., Kretzschmar R., Stahr K. and Wilke B.-M. (2016) Scheffer/Schachtschabel - Soil Science. 16th ed., Springer, 
Heidelberg.

Bolanz R. M., Wierzbicka-Wieczorek M., Čaplovičová M., Uhlík P., Göttlicher J., Steininger R. and Majzlan J. (2013) Structural Incorporation of $\mathrm{As}^{5+}$ into Hematite. Environ. Sci. Technol. 47, 9140-9147.

Brunauer S., Emmett P. H. and Teller E. (1938) Gases in Multimolecular Layers. J. Am. Chem. Soc. 60, 309-319.

Catalano J. G., Zhang Z., Fenter P. and Bedzyk M. J. (2006) Inner-sphere adsorption geometry of $\mathrm{Se}(\mathrm{IV})$ at the hematite (100)-water interface. J. Colloid Interface Sci. 297, 665-671.

Chen F., Burns P. C. and Ewing R. C. (1999) ${ }^{79}$ Se: geochemical and crystallo-chemical retardation mechanisms. J. Nucl. Mater. 275, 81-94.

Christophersen O. A., Lyons G., Haug A. and Steinnes E. (2012) Selenium. In Heavy Metals in Soils: Trace Metals and Metalloids in Soils and their Bioavailability (ed. B. J. Alloway). Springer, Dordrecht, NL. pp. 429-464.

Cornell R. M. and Schwertmann U. (2003) The iron oxydes: Structure, Properties, Reactions, Occurences and Uses. 2nd ed., Wiley-VCH, Weinheim.

Das S., Essilfie-Dughan J. and Hendry M. J. (2015) Fate of adsorbed arsenate during phase transformation of ferrihydrite in the presence of gypsum and alkaline conditions. Chem. Geol. 411, 69-80.

Das S., Hendry J. M. and Essilfie-Dughan J. (2013) Adsorption of selenate onto ferrihydrite, goethite, and lepidocrocite under neutral $\mathrm{pH}$ conditions. Appl. Geochemistry 28, 185-193.

Dhillon K. S. and Dhillon S. K. (2003) Distribution and management of seleniferous soils. Adv. Agron. 79, 119-184.

Doornbusch B., Bunney K., Gan B. K., Jones F. and Gräfe M. (2015) Iron oxide formation from $\mathrm{FeCl}_{2}$ solutions in the presence of uranyl $\left(\mathrm{UO}_{2}{ }^{2+}\right)$ cations and carbonate rich media. Geochim. Cosmochim. Acta 158, 22-47.

Duc M., Lefèvre G. and Fédoroff M. (2006) Sorption of selenite ions on hematite. J. Colloid Interface Sci. 298, 556-563.

Duc M., Lefèvre G., Fédoroff M., Jeanjean J., Rouchaud J. C., Monteil-Rivera F., Dumonceau J. and Milonjic S. (2003) Sorption of selenium anionic species on apatites and iron oxides from aqueous solutions. J. Environ. Radioact. 70, 61-72.

Fernández-Martínez A. and Charlet L. (2009) Selenium environmental cycling and bioavailability: A structural chemist point of view. Rev. Environ. Sci. Biotechnol. 8, 81-110.

Fukushi K. and Sverjensky D. A. (2007) A surface complexation model for sulfate and selenate on iron oxides consistent with spectroscopic and theoretical molecular evidence. Geochim. Cosmochim. Acta 71, 1-24.

Gálvez N., Barrón V. and Torrent J. (1999a) Effect of phosphate on the crystallization of hematite, goethite, and lepidocrocite from ferrihydrite. Clays Clay Miner. 47, 304-311.

Gálvez N., Barrón V. and Torrent J. (1999b) Preparation and Properties of Hematite with Structural Phosphorus. Clays Clay Miner. 47, 375-385.

Giester G. and Pertlik F. (1994) Synthesis and crystal structure of iron(III) selenate(IV) trihydrate, $\mathrm{Fe}_{2}\left(\mathrm{SeO}_{3}\right)_{3} \cdot 3 \mathrm{H}_{2} \mathrm{O}$. J. Alloys Compd. 210, 125-128.

Grambow B. (2008) Mobile fission and activation products in nuclear waste disposal. J. Contam. Hydrol. 102, 180-186. 
Hawthorne F. C. (1984) The crystal structure of mandarinoite, $\mathrm{Fe}^{3+}{ }_{2} \mathrm{Se}_{3} \mathrm{O}_{9} \cdot 6 \mathrm{H}_{2} \mathrm{O}$. Can. Mineral. 22, $475-480$.

Hayes K. F., Roe A. L., Brown G. E., Hodgson K. O., Leckie J. O. and Parks G. A. (1987) In Situ X-

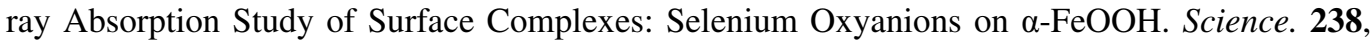
783-786.

Hiemstra T., Rietra R. P. J. J. and Van Riemsdijk W. H. (2007) Surface Complexation of Selenite on Goethite: MO/DFT Geometry and Charge Distribution. Croat. Chem. Acta 80, 313-324.

Jordan N., Ritter A., Foerstendorf H., Scheinost A. C., Weiß S., Heim K., Grenzer J., Mücklich A. and Reuther H. (2013) Adsorption mechanism of selenium(VI) onto maghemite. Geochim. Cosmochim. Acta 103, 63-75.

Jordan N., Ritter A., Scheinost A. C., Weiss S., Schild D. and Hübner R. (2014) Selenium(IV) uptake by maghemite $\left(\gamma-\mathrm{Fe}_{2} \mathrm{O}_{3}\right)$. Environ. Sci. Technol. 48, 1665-1674.

Kämpf N., Scheinost A. C. and Schulze D. G. (2011) Oxide Minerals in Soils. In Handbook of Soil Sciences: Properties and Processes (eds. P. M. Huang, Y. Li, and M. E. Sumner). CRC Press, Boca Raton, USA. p. 1442.

Lenz M. and Lens P. N. L. (2009) The essential toxin: The changing perception of selenium in environmental sciences. Sci. Total Environ. 407, 3620-3633.

Liu J., Liang C., Zhang H., Tian Z. and Zhang S. (2012) General Strategy for Doping Impurities (Ge, Si, Mn, Sn, Ti) in Hematite Nanocrystals. J. Phys. Chem. 116, 4986-4992.

Manceau A. and Charlet L. (1994) The Mechanism of Selenate Adsorption on Goethite and Hydrous Ferric Oxide. J. Colloid Interface Sci. 168, 87-93.

Martínez M., Giménez J., de Pablo J., Rovira M. and Duro L. (2006) Sorption of selenium(IV) and selenium(VI) onto magnetite. Appl. Surf. Sci. 252, 3767-3773.

Missana T., Alonso U., Scheinost A. C., Granizo N. and García-Gutiérrez M. (2009) Selenite retention by nanocrystalline magnetite: Role of adsorption, reduction and dissolution/co-precipitation processes. Geochim. Cosmochim. Acta 73, 6205-6217.

Mitchell K., Couture R.-M., Johnson T. M., Mason P. R. D. and Van Cappellen P. (2013) Selenium sorption and isotope fractionation: Iron(III) oxides versus iron(II) sulfides. Chem. Geol. 342, 2128.

Neal R. H. (1995) Selenium. In Heavy Metals in Soils (ed. B. J. Alloway). Blackie Academic \& Professional, London, UK. pp. 260-283.

Ona-Nguema G., Morin G., Juillot F., Calas G. and Brown G. E. (2005) EXAFS Analysis of Arsenite Adsorption onto Two-Line Ferrihydrite, Hematite, Goethite, and Lepidocrocite. Environ. Sci. Technol. 39, 9147-9155.

Parida K. M., Gorai B., Das N. N. and Rao S. B. (1997) Studies on ferric oxide hydroxides - III. Adsorption of selenite $\left(\mathrm{SeO}_{3}{ }^{2-}\right)$ on different forms of iron oxyhydroxides. J. Colloid Interface Sci. 185, 355-362.

Peak D. and Sparks D. L. (2002) Mechanisms of selenate adsorption on iron oxides and hydroxides. Environ. Sci. Technol. 36, 1460-1466.

Ressler T. (1998) WinXAS: a program for X-ray absorption spectroscopy data analysis under MSWindows. J. Synchrotron Radiat. 5, 118-122.

Rietra R. P. J. J., Hiemstra T. and van Riemsdijk W. H. (2001) Comparison of Selenate and Sulfate Adsorption on Goethite. J. Colloid Interface Sci. 240, 384-390.

Roh Y., Lee S. Y. and Elless M. P. (2000) Characterization of corrosion products in the permeable 
reactive barriers. Environ. Geol. 40, 184-194.

Rossberg A., Reich T. and Bernhard G. (2003) Complexation of uranium(VI) with protocatechuic acid-application of iterative transformation factor analysis to EXAFS spectroscopy. Anal. Bioanal. Chem. 376, 631-638.

Rovira M., Giménez J., Martínez M., Martínez-Lladó X., de Pablo J., Martí V. and Duro L. (2008) Sorption of selenium(IV) and selenium(VI) onto natural iron oxides: Goethite and hematite. $J$. Hazard. Mater. 150, 279-284.

Scheinost A. C. and Charlet L. (2008) Selenite reduction by mackinawite, magnetite and siderite: XAS characterization of nanosized redox products. Environ. Sci. Technol. 42, 1984-1989.

Scheinost A. C., Rossberg A., Vantelon D., Xifra I., Kretzschmar R., Leuz A. K., Funke H. and Johnson C. A. (2006) Quantitative antimony speciation in shooting-range soils by EXAFS spectroscopy. Geochim. Cosmochim. Acta 70, 3299-3312.

Schwertmann U. and Cornell R. M. (2000) Iron oxides in the laboratory: Preparation and characterization. 2nd ed., Wiley-VCH, Weinheim.

Schwertmann U., Stanjek H. and Becher H.-H. (2004) Long-term in vitro transformation of 2-line ferrihydrite to goethite/hematite at $4,10,15$ and $25^{\circ} \mathrm{C}$. Clay Miner. 39, 433-438.

Séby F., Potin-Gautier M., Giffaut E., Borge G. and Donard O. F. X. (2001) A critical review of thermodynamic data for selenium species at $25^{\circ} \mathrm{C}$. Chem. Geol. 171, 173-194.

Skomurski F. N., Rosso K. M., Krupka K. M. and McGrail B. P. (2010) Technetium Incorporation into Hematite $\left(\alpha-\mathrm{Fe}_{2} \mathrm{O}_{3}\right)$. Environ. Sci. Technol. 44, 5855-5861.

Soltis J. A., Feinberg J. M., Gilbert B. and Penn R. L. (2016) Phase Transformation and ParticleMediated Growth in the Formation of Hematite from 2-Line Ferrihydrite. Cryst. Growth Des. 16, 922-932.

Sparks D. L. (2003) Environmental Soil Chemistry. 2nd ed., Academic Press, Amsterdam, NL.

Sracek O. (2015) Formation of secondary hematite and its role in attenuation of contaminants at mine tailings: review and comparison of sites in Zambia and Namibia. Front. Environ. Sci. 2, 1-11.

Su C. and Suarez D. L. (2000) Selenate and Selenite Sorption on Iron Oxides. Soil Sci. Soc. Am. J. 64, $101-111$.

Trainor T. P., Chaka A. M., Eng P. J., Newville M., Waychunas G. A., Catalano J. G. and Brown G. E. (2004) Structure and reactivity of the hydrated hematite (0001) surface. Surf. Sci. 573, 204-224.

Wijnja H. and Schulthess C. P. (2002) Effect of Carbonate on the Adsorption of Selenate and Sulfate on Goethite. Soil Sci. Soc. Am. J. 66, 1190-1197.

Wijnja H. and Schulthess C. P. (2000) Vibrational Spectroscopy Study of Selenate and Sulfate Adsorption Mechanisms on Fe and Al (Hydr)oxide Surfaces. J. Colloid Interface Sci. 229, 286297.

Winkel L. H. E., Johnson C. A., Lenz M., Grundl T., Leupin O. X., Amini M. and Charlet L. (2012) Environmental selenium research: From microscopic processes to global understanding. Environ. Sci. Technol. 46, 571-579.

Winkel L. H. E., Vriens B., Jones G. D., Schneider L. S., Pilon-Smits E. and Bañuelos G. S. (2015) Selenium Cycling Across Soil-Plant-Atmosphere Interfaces: A Critical Review. Nutrients 7, 4199-4239.

Zhang P. and Sparks D. L. (1990) Kinetics of selenate and selenite adsorption/desorption at the goethite/water interface. Environ. Sci. Technol. 24, 1848-1856. 


\section{Figures in the article}

Fig. 1. Adsorption (Ads) of $\mathrm{Se}(\mathrm{VI})$ and $\mathrm{Se}(\mathrm{VI})$ by hematite $(\mathrm{Hm})$ at $\mathrm{m} / \mathrm{V}$ of $9.0 \mathrm{~g} / \mathrm{L}$. (Left) $\mathrm{Se}(\mathrm{IV})$ and $\mathrm{Se}(\mathrm{VI})$ adsorption onto hematite depending on $\mathrm{pH}$ and ionic strength (IS) at initial Se concentrations of $10^{-4} \mathrm{~mol} / \mathrm{L}$. (Right) Uptake of $\mathrm{Se}(\mathrm{IV})$ and $\mathrm{Se}(\mathrm{VI})$ by hematite at $\mathrm{pH} 7.5$ as a function of the Se equilibrium concentration.

Fig. 2. Uptake of $\mathrm{Se}(\mathrm{IV})$ and $\mathrm{Se}(\mathrm{VI})$ by hematite $(\mathrm{Hm})$ during coprecipitation (Cop) and adsorption (Ads) as a function of the Se equilibrium concentration.

Fig. 3. Cumulative Se desorption from hematite adsorption (Ads) and coprecipitation (Cop) experiments after 3 washing steps at $\mathrm{pH} 12\left(0.01 \mathrm{M} \mathrm{KNO}_{3}\right)$. Sorption conditions: $\mathrm{m} / \mathrm{V}=9.0 \mathrm{~g} / \mathrm{L} ;(\mathrm{a}) \mathrm{c}(\mathrm{Se})_{0}=10^{-4} \mathrm{~mol} / \mathrm{L} \approx \rho(\mathrm{Se})=8$ $\mathrm{mg} / \mathrm{L} ;(\mathrm{b}) \mathrm{c}(\mathrm{Se})_{0}=10^{-3} \mathrm{~mol} / \mathrm{L} \approx \rho(\mathrm{Se})=80 \mathrm{mg} / \mathrm{L}$.

Fig. 4. Cumulative desorption of Se(IV) from hematite $(\mathrm{Hm})$ and ferrihydrite (Fh) adsorption (Ads) and coprecipitation (Cop) experiments as a function of $\mathrm{OH}^{-}$concentration. Initial Se concentration during the sorption step: $\mathrm{c}(\mathrm{Se})_{0}=10^{-3} \mathrm{~mol} / \mathrm{L}$.

Fig. 5. Time-resolved XRD analysis (Cu Ka) of the transformation of 2-line ferrihydrite (broad peaks with maxima at $2 \theta$ of $\sim 35^{\circ}$ and $\sim 62^{\circ}$ ) into crystalline hematite. Shown are 3 selected time steps for a series of $\mathrm{Se}$ (IV) coprecipitated hematite samples $\left(\mathrm{c}(\mathrm{Se})_{0}=10^{-3} \mathrm{~mol} / \mathrm{L}\right)$. All peaks of crystalline phases are associated with hematite and $\mathrm{KNO}_{3}$ (precipitated background electrolyte)

Fig. 6. Development of the Se concentration during the coprecipitation (Cop) of hematite ( $\mathrm{Hm})$. This includes the fast precipitation of the precursor phase ferrihydrite (Fh) in 4 steps and its subsequent transformation into hematite. Initial concentrations of $\mathrm{Se}(\mathrm{IV})$ and $\mathrm{Se}(\mathrm{VI}): 10^{-3} \mathrm{~mol} / \mathrm{L}$.

Fig. 7. SEM images of hematite $(\mathrm{Hm})$ samples of coprecipitation (Cop) and adsorption (Ads) experiments with $\mathrm{Se}(\mathrm{VI})$ and $\mathrm{Se}(\mathrm{VI})$. Initial Se concentration of all samples: $4 \cdot 10^{-3} \mathrm{~mol} / \mathrm{L}$. (a) Se(VI) coprecipitation with hematite, (b) $\mathrm{Se}(\mathrm{VI})$ adsorption onto hematite, (c) Se(IV) coprecipitation with hematite; formation of a hematite-goethite mixed phase, (d) Se(IV) adsorption onto hematite

Fig. 8. Se K-edge XANES and EXAFS spectra of $\mathrm{Se}(\mathrm{IV})$ and $\mathrm{Se}(\mathrm{VI})$ bearing hematite $(\mathrm{Hm})$ and ferrihydrite $(\mathrm{Fh})$ samples of different coprecipitation (Cop) and adsorption (Ads) studies. (If not otherwise indicated, EXAFS Fourier transforms (FT) were calculated over the k-range 3-14.5 $\AA^{-1}$ )

Fig. 9. Iterative transformation factor analysis of Se K-edge EXAFS spectra. Left: Experimental FT spectra (black lines) and their reconstruction (red lines) by two principal components (PC). EXAFS Fourier transforms were calculated over the k-range 2-10.5 $\AA^{-1}$. Right: Varimax loadings of the spectral components.

Fig. 10. Schematic representation of the uptake mechanisms of Se oxyanions by hematite. This includes an outer-sphere adsorption of $\mathrm{Se}(\mathrm{VI})$, the formation of inner-sphere $\mathrm{Se}(\mathrm{IV})\left({ }^{2} \mathrm{E}\right.$ or $\left.{ }^{2} \mathrm{C}\right)$ complexes and the incorporation of Se oxyanions as a result of the ferrihydrite-hematite recrystallization. 


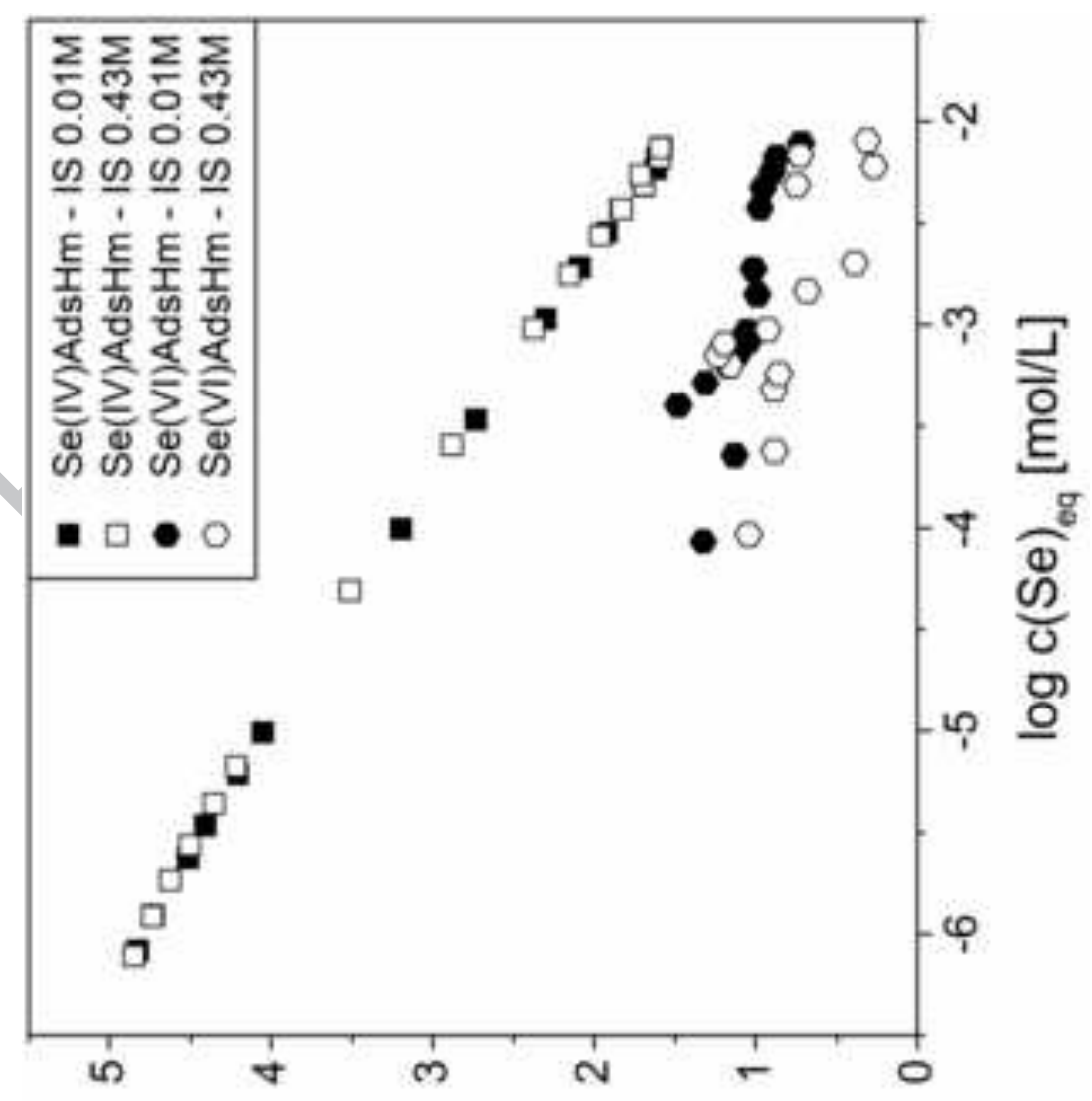

[6y/7] ${ }^{p}$ y्र 60이

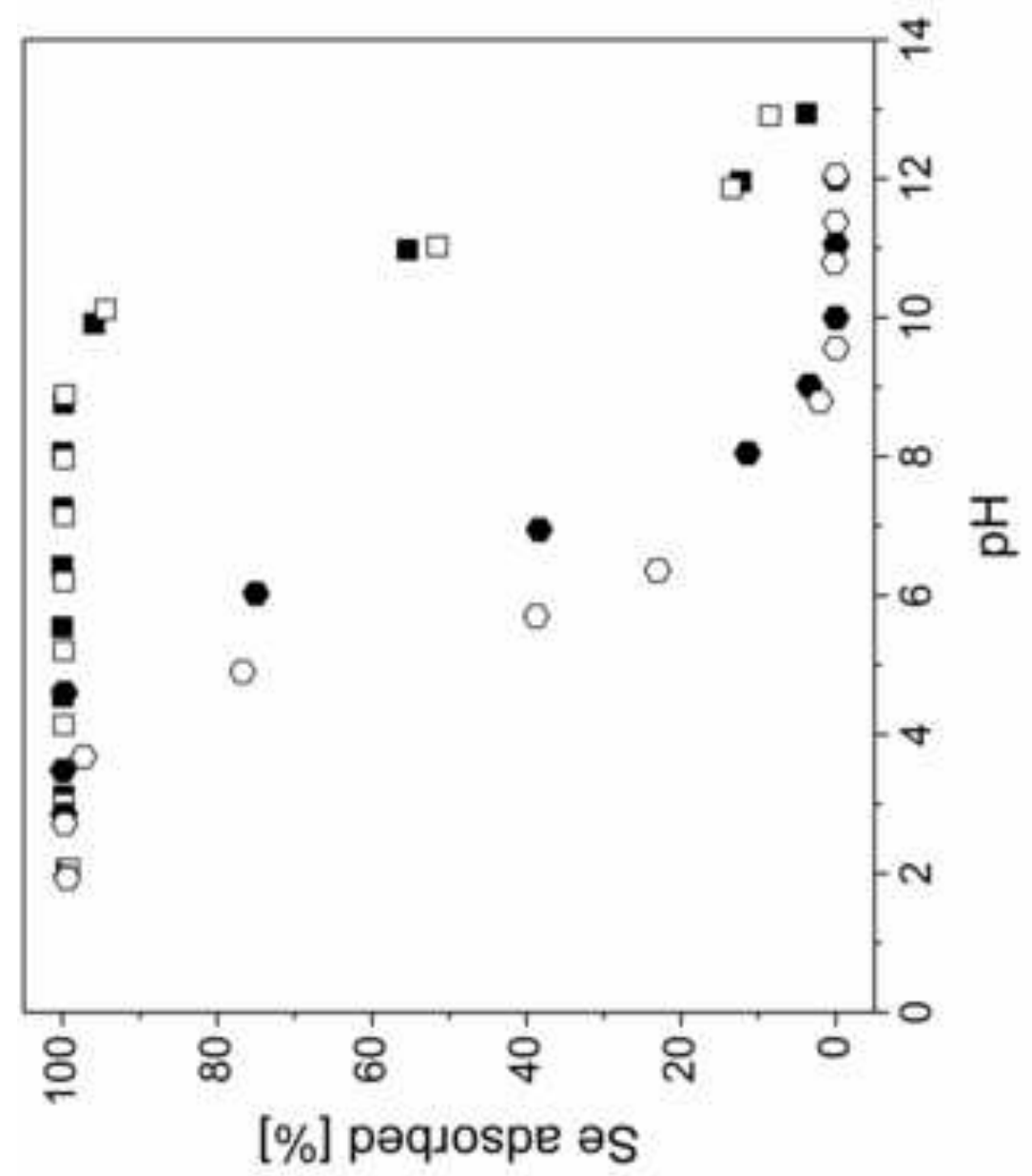




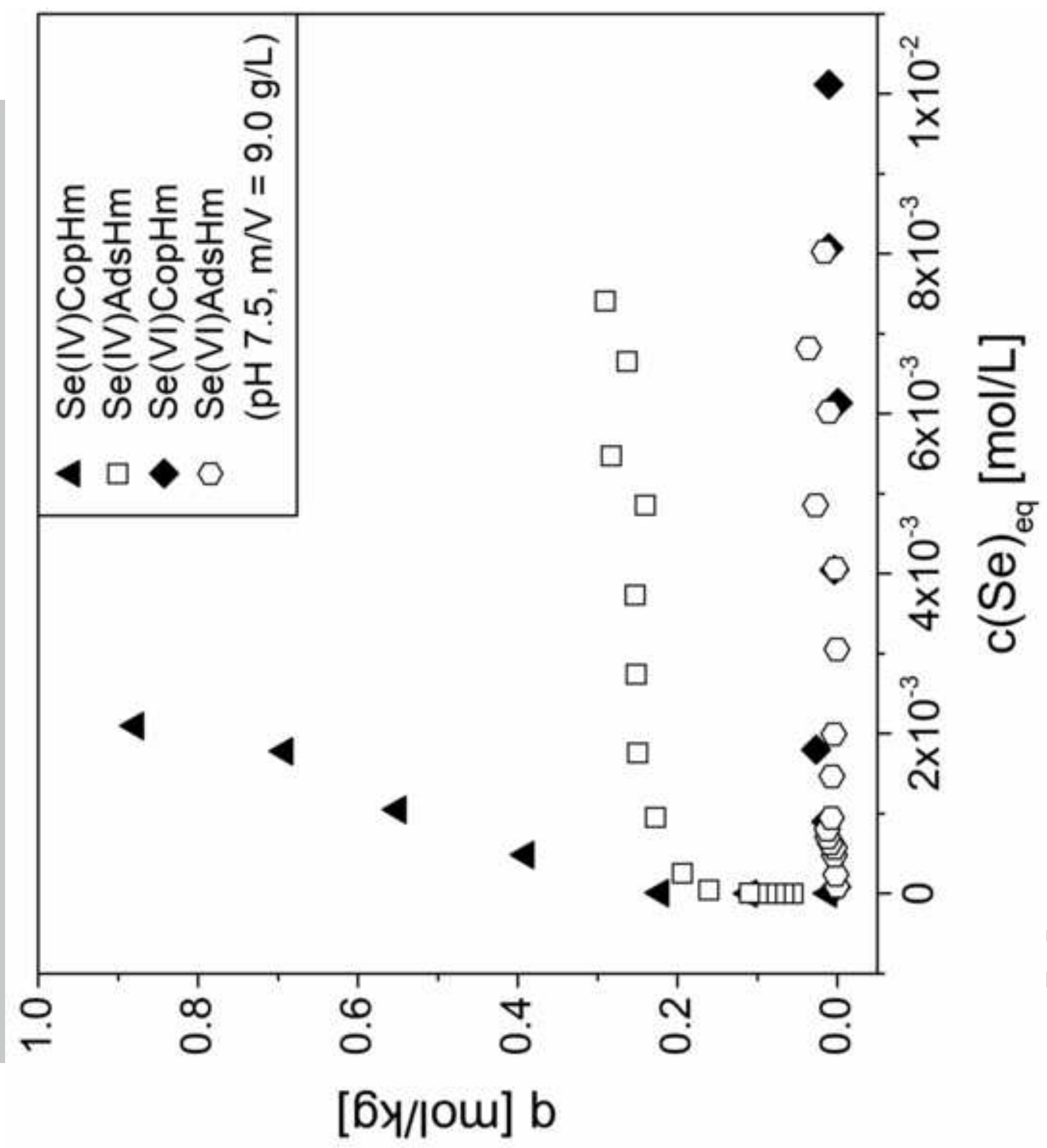



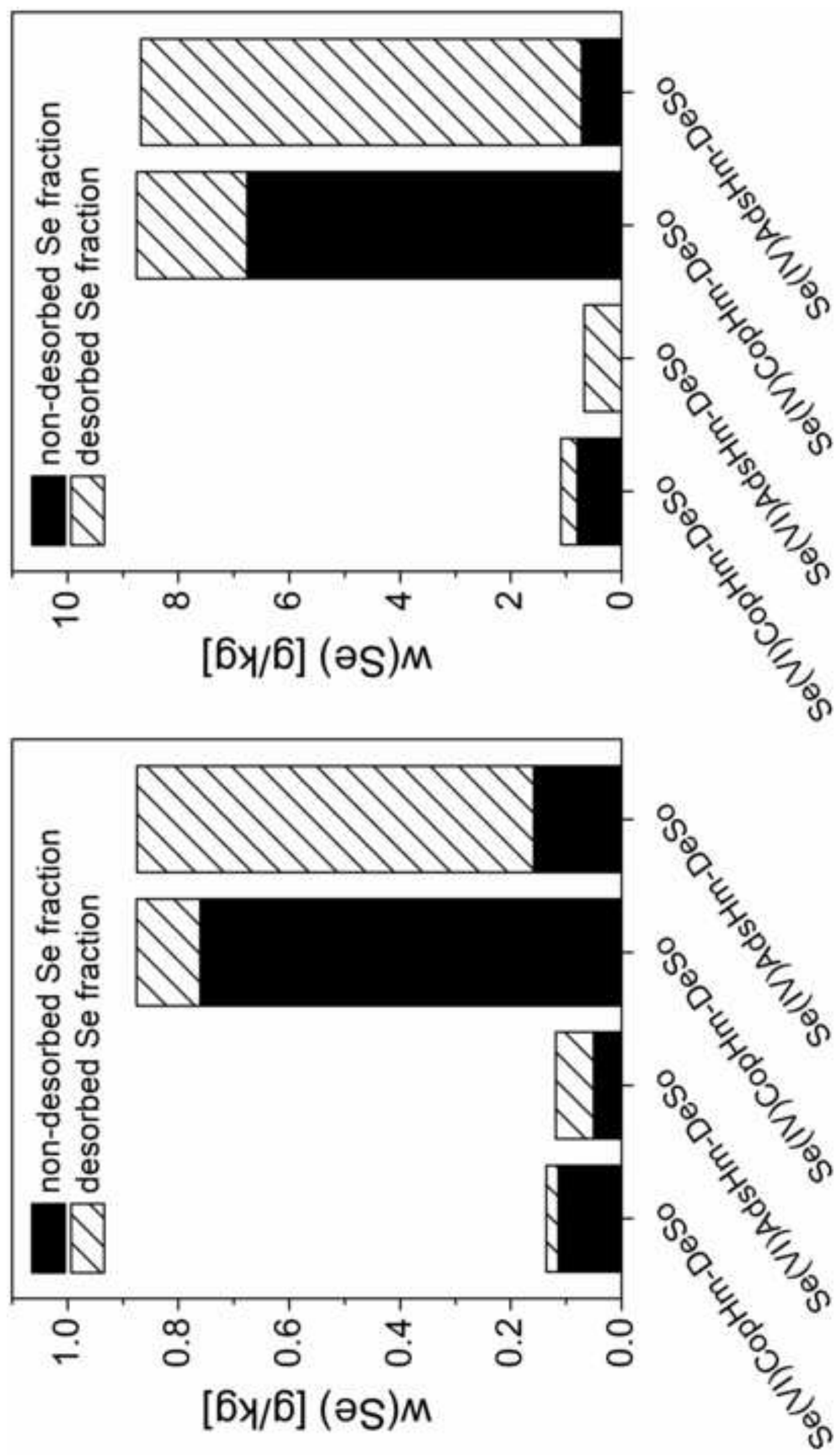


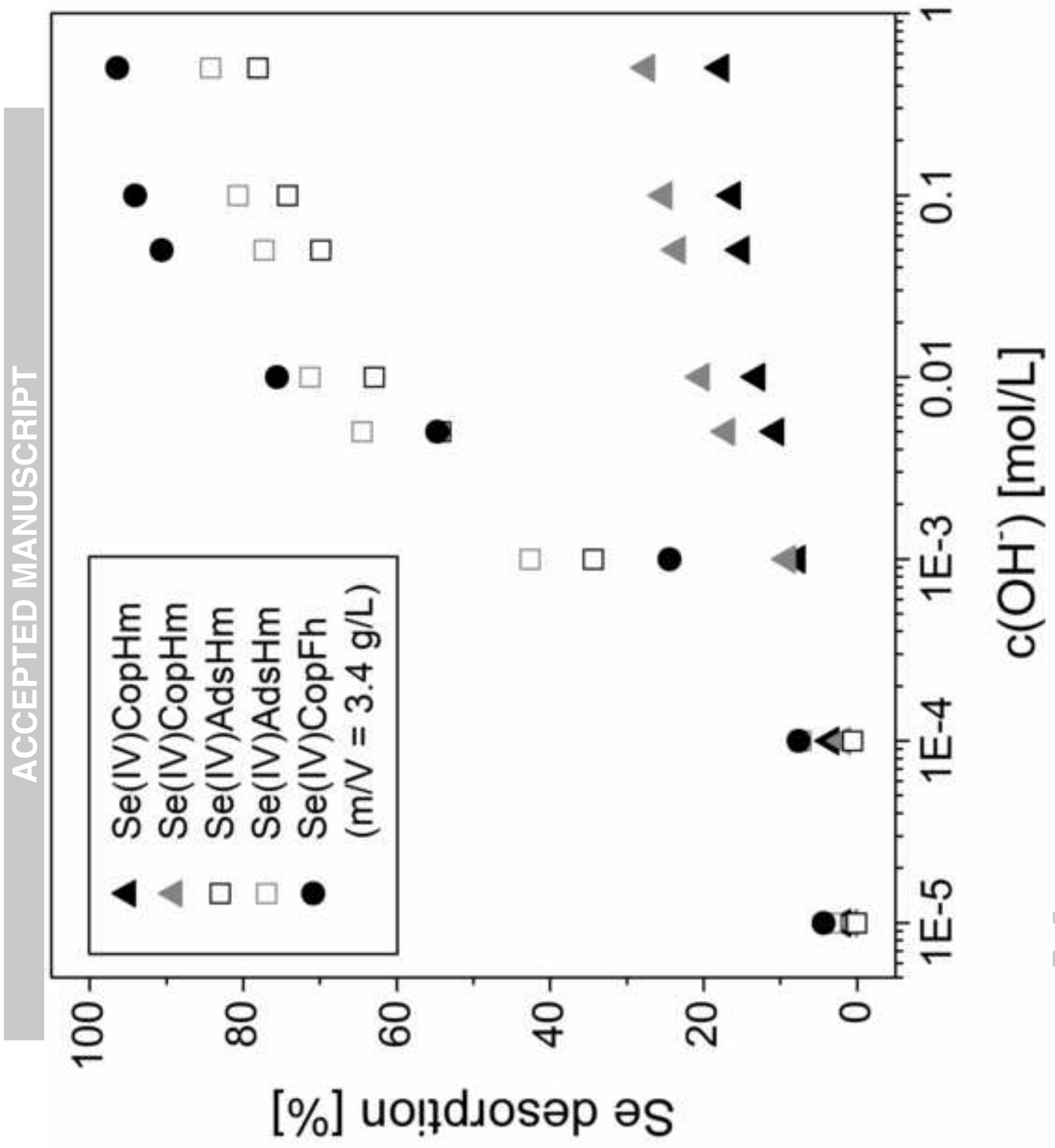




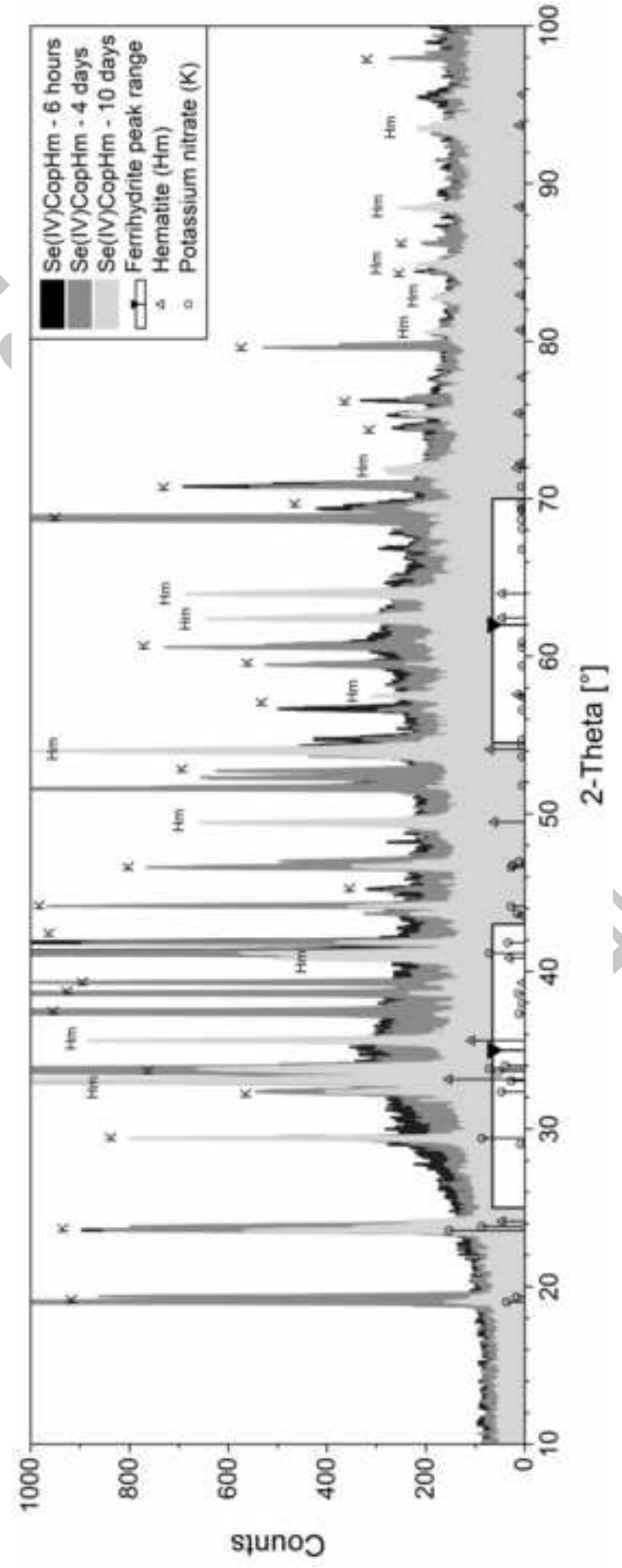




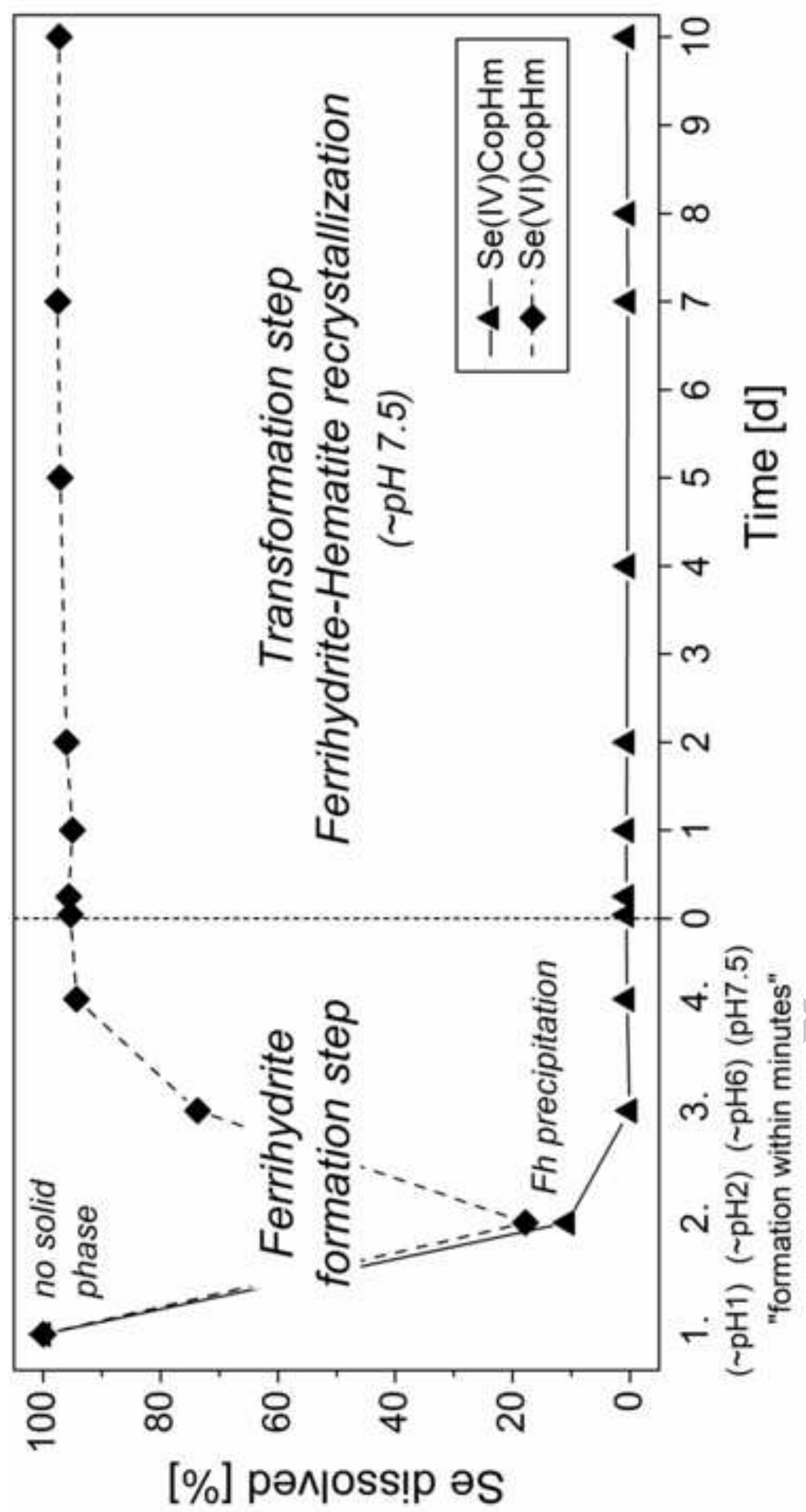




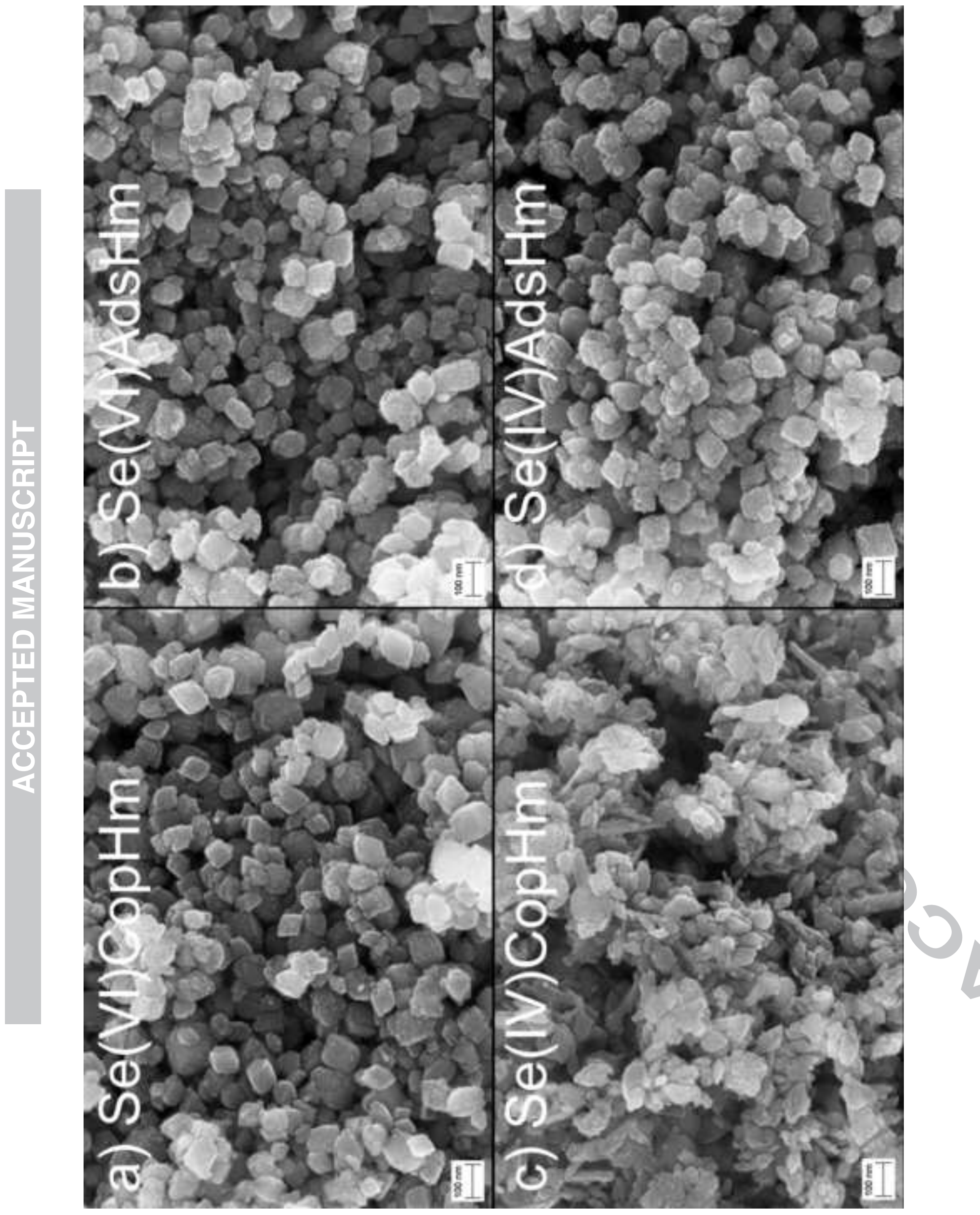




\section{ACCEPTED MANUSCRIPT}

Interaction of $\mathrm{Se}(\mathrm{VI})$ with hematite

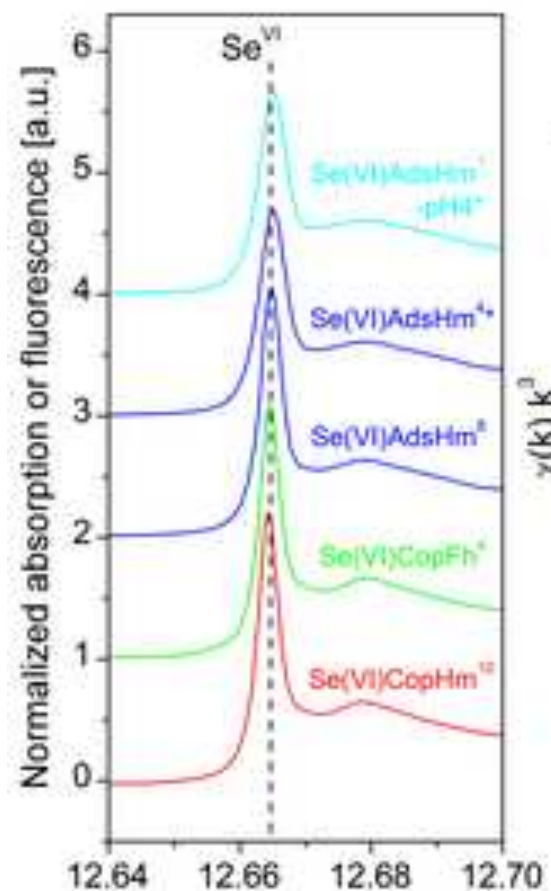

Photon energy [keV]
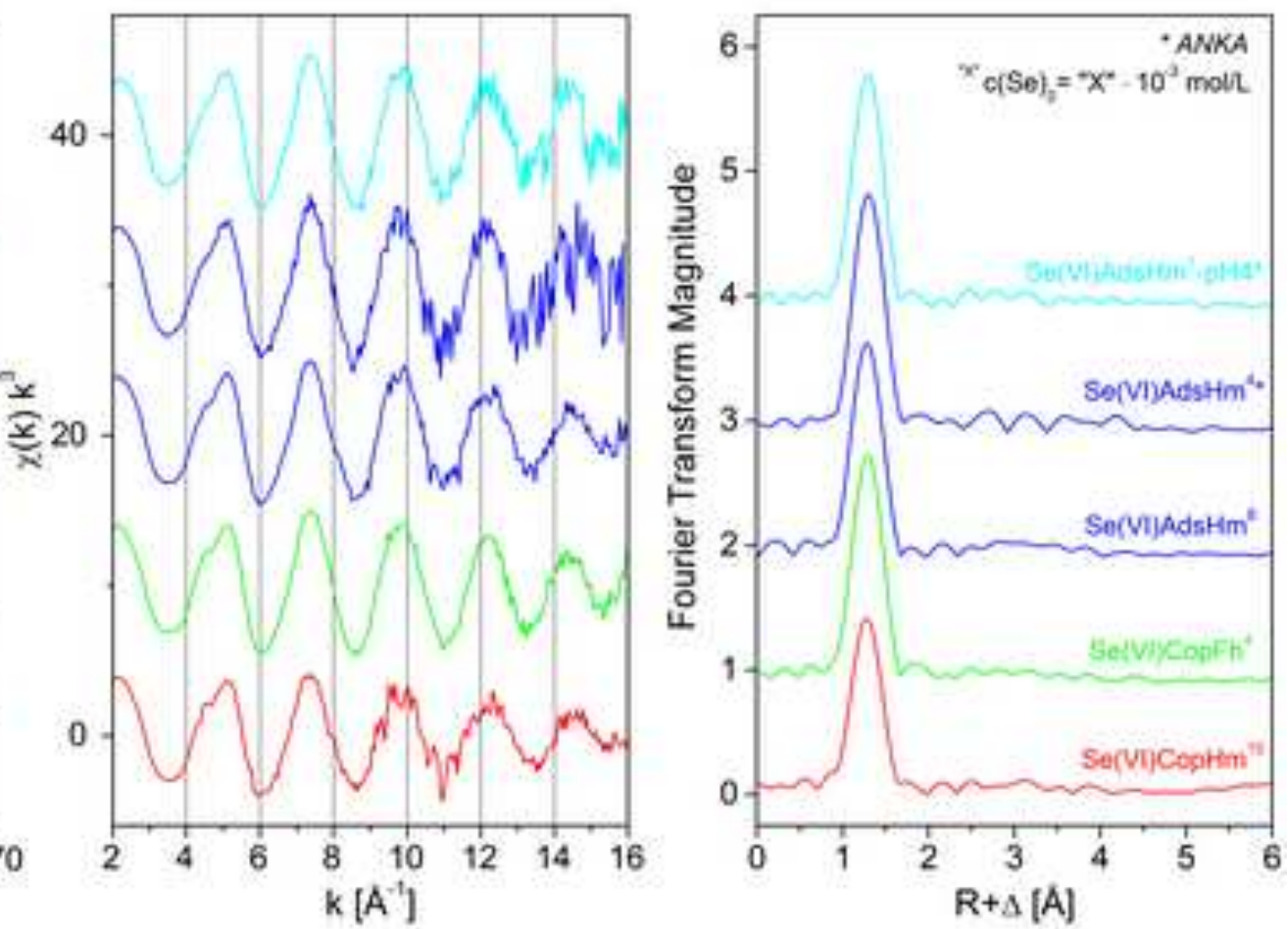

Interaction of Se(IV) with hematite

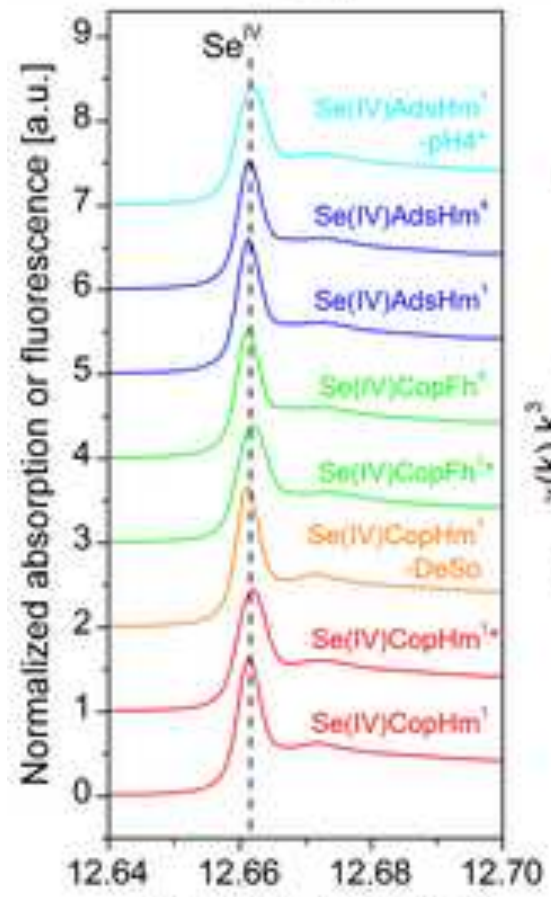

Photon energy [keV]
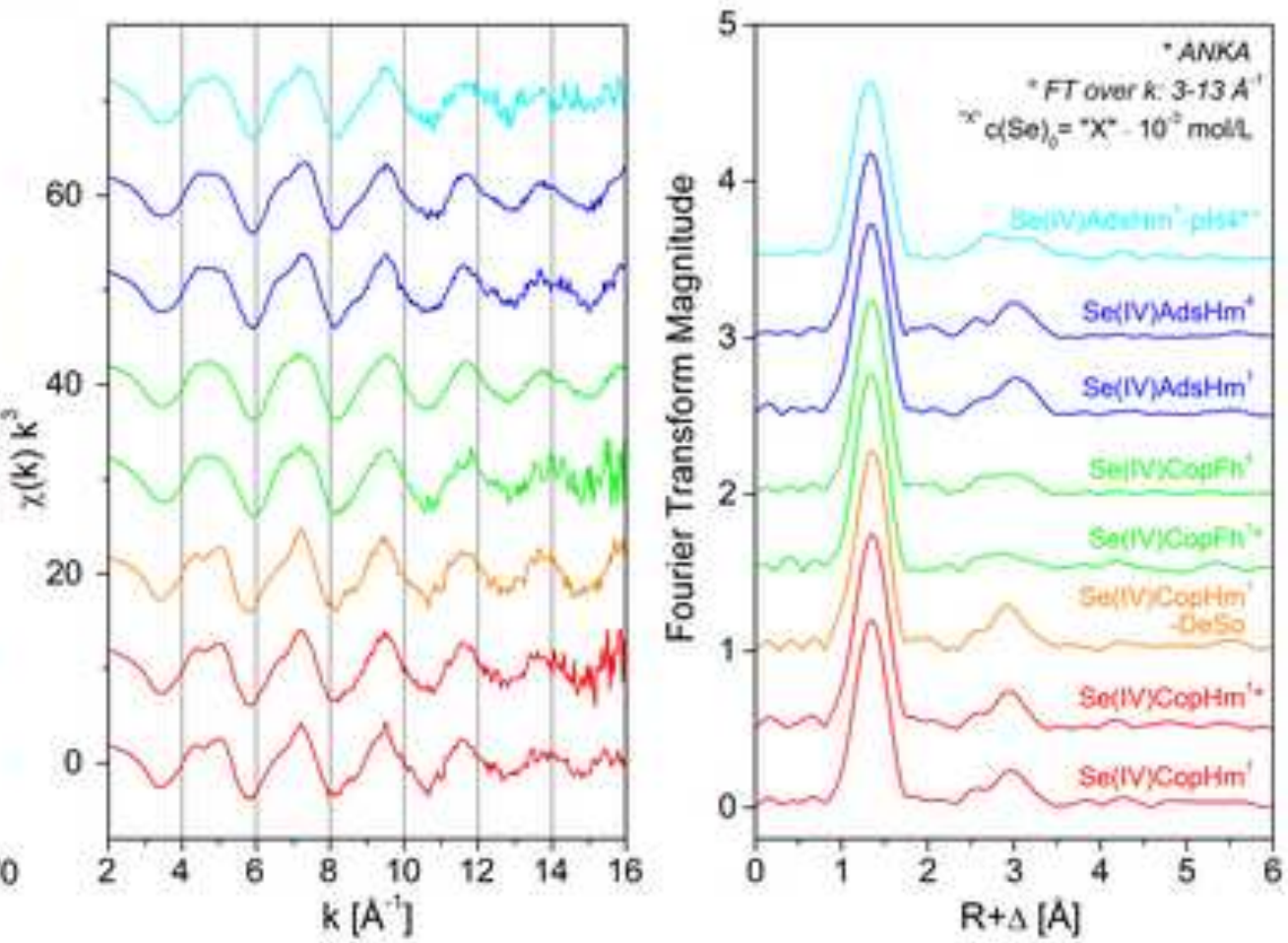

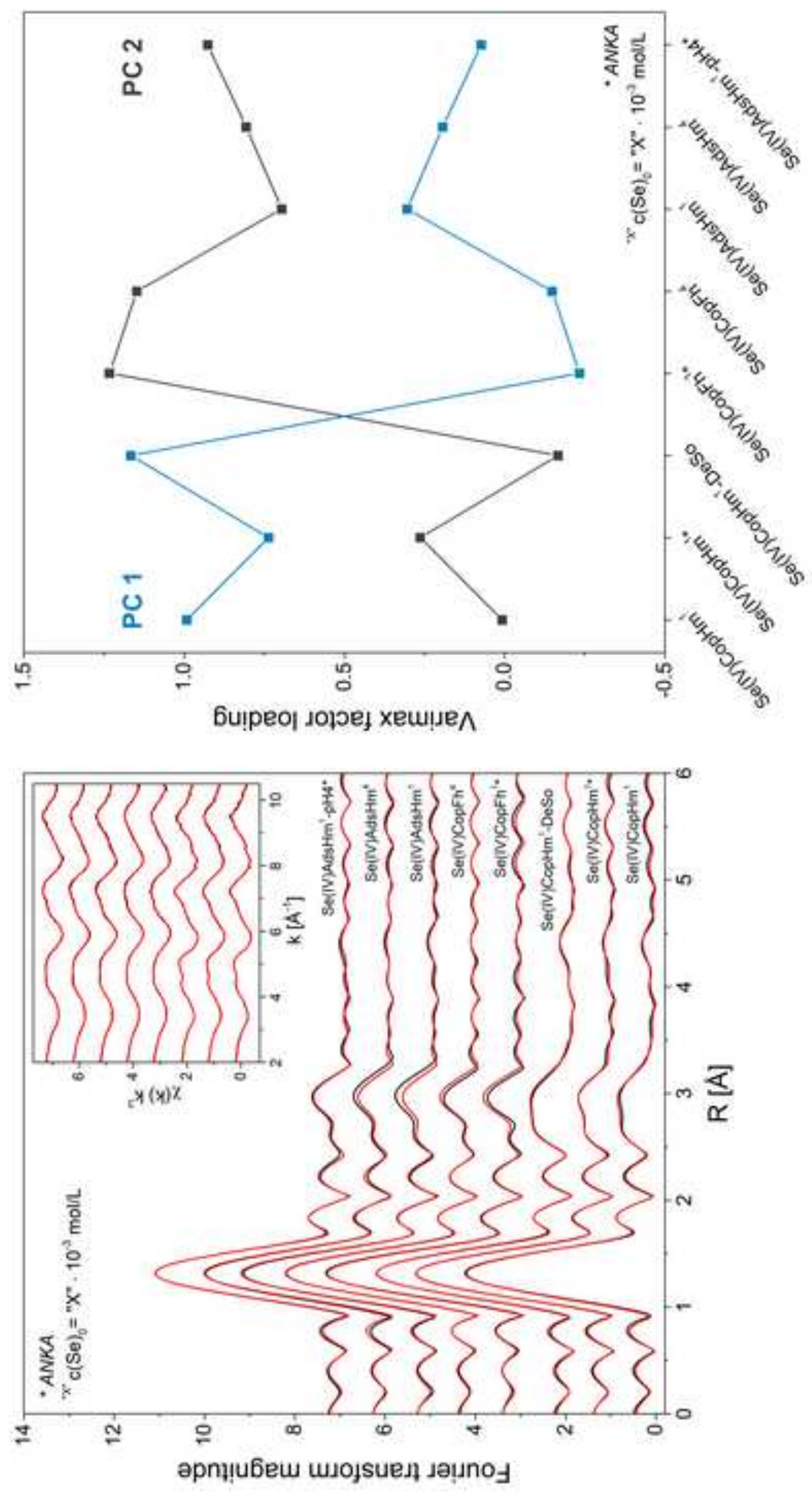

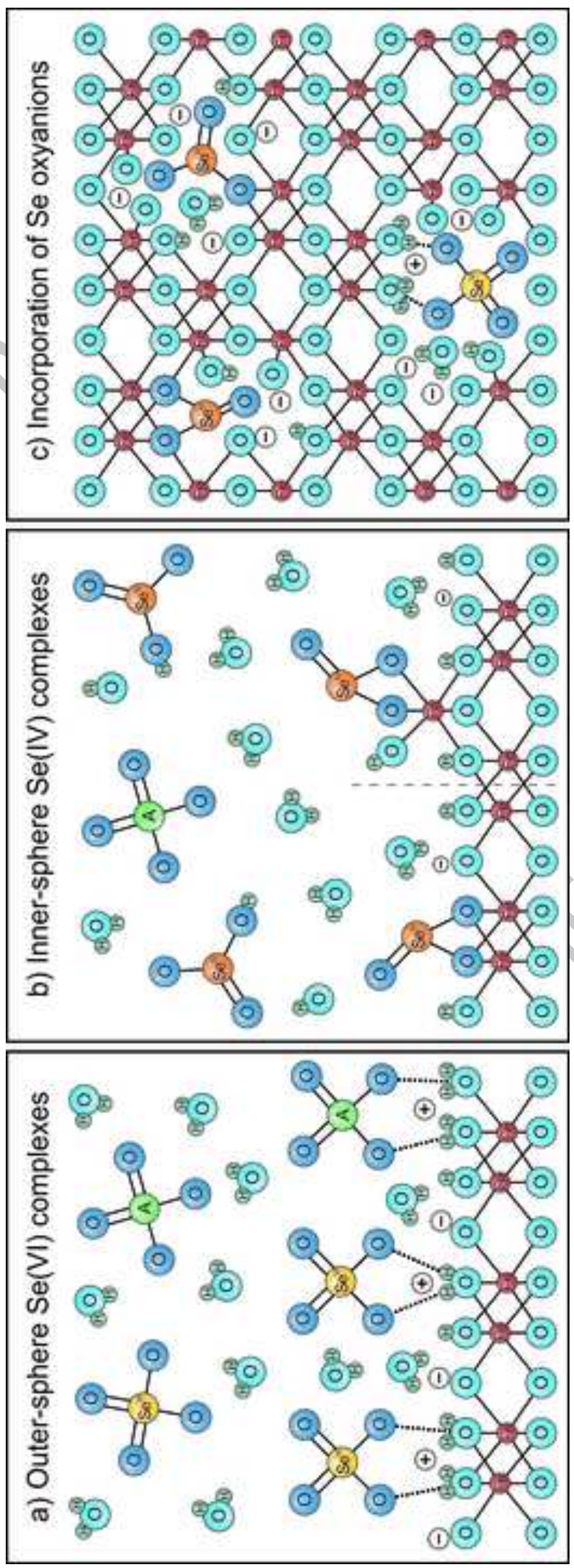